\title{
Co-present and remote audience experiences: intensity and cohesion
}

\author{
Erik Geelhoed $^{1}$ (D) $\cdot$ Kuldip Singh-Barmi $^{1} \cdot \operatorname{Ian}_{\text {Biscoe }^{1}} \cdot$ \\ Pablo Cesar $^{2}$ - Jack Jansen ${ }^{2}$. Chen Wang ${ }^{2}$. \\ Rene Kaiser $^{3}$
}

Received: 5 January 2016 / Revised: 3 July 2016 / Accepted: 16 August 2016 /

Published online: 15 September 2016

(C) Springer Science+Business Media New York 2016

\begin{abstract}
This article presents the results of modelling audience response to new types of networked theatre plays. As the main contribution of the work we introduce two types of metrics: intensity, relating to how intensively co-present and remote aspects of a performance are rated, and cohesion, relating to how a performance as a whole, the combination of copresent and remote aspects, affects an audience. In particular, we model audience response based on two in the wild evaluations, staged by a low budget theatre company, a streamed and a distributed performance. The streamed performance is similar to NT Live, where a theatre play is delivered to other theatres with an audience. The distributed performance, on the other hand, connects actors in two different theatres (with audiences) creating one single play. The streamed performance was experienced as less intense as well as less cohesive by the remote audience, whilst the distributed performance integrated co-present and remote aspects tightly. Remote aspects of the distributed performance were still experienced as less intense, but the performance as a whole was highly cohesive. Apart from the identification of these two new metrics (intensity and cohesion), based on our experiences we argue that an innovative way of bundling relevant emerging technologies is needed to give a voice to the, as yet silent, remote audience.
\end{abstract}

Erik Geelhoed

erik.geelhoed@falmouth.ac.uk

Pablo Cesar

P.S.Cesar@cwi.nl

Rene Kaiser

rene.kaiser@joanneum.at

1 Falmouth University, Falmouth, UK

2 Centrum Wiskunde \& Informatica, Amsterdam, Netherlands

3 Institute for Information and Communication Technologies, JOANNEUM RESEARCH, Graz, Austria 
Keywords Distributed performances $\cdot$ Streaming performances $\cdot$ Evaluation methods $\cdot$ Media experiences $\cdot$ Audience evaluation $\cdot$ Audience feedback $\cdot$ Telepresence

\section{Introduction}

Over the past decade, major performing arts companies have streamed live performances to remote locations, most often cinemas $[3,12]-$ e.g. National Theatre in the UK, New York Metropolitan Opera and CultureHub [20] in the USA. Streaming live performances across the world strengthens the brand of theatres, and increases revenues. Augmenting existing (co-present) theatre audiences with paying remote audiences, beyond national borders, has artistic and commercial impact. However, the phenomenon is still in its infancy, and current (mainstream) solutions have limitations. This article focuses on one specific limitation: evaluating the audience response of connected performances. In particular, it introduces two relevant metrics for such type of evaluation: intensity and cohesion.

This article aims at modelling relevant metrics for evaluating audience experience. The modelling is based on the results of two studies in the wild, as a result of our collaboration with Miracle Theatre Company:

- A comparison between a live performance and a streamed performance [7].

- An evaluation of the audience response to a distributed performance where the action took place between two connected stages with audiences in both locations.

In line with the literature on telepresence, we define the audience that attends a live performance as the co-present audience and the audience that attends a streamed performance as the remote audience. Similarly when we evaluate a distributed performance, we distinguish between co-present aspects of the performance (action and actors physically in the room with the audience) and remote aspects (perceiving action and actors in the remote location).

In the first study, live streaming, a live theatre performance was captured using broadcast quality cameras and microphones, and narrow-casted to a cinema with an audience (the remote audience), with a large screen and good quality audio reproduction. The viewing and social context is rather different than sitting at home and watching a live theatre performance in the living room on a TV. This novel type of networked performances is of interest to mainstream theatre companies that already regularly stream their productions to remote locations: the 'mainstream streamers'. For them, we describe a quick and clean method for collecting and analysing quantitative audience feedback to live and streamed performances.

The second study, distributed performance, is more targeted at non-mainstream theatre companies that specialise in novel types of artistic expression. In this case, the production is being played out between two or more Internet connected (geographically distributed) stages. In this case we evaluated the reaction of the audience to an adapted version of Miracle Theatre's stage production of Shakespeare's The Tempest, using two connected theatre spaces, each with its own audience. More information about the show and the technology enabling such a setup can be found in previous publications [32, 72, 73].

Based on these studies, and previous feedback from performers [27] and performance companies [45], our core research contributions are: 
- To introduce two new concepts for measuring audience experience of networked theatre: intensity and cohesion.

- To outline a sensitive method of quantifying the differences in experience of an audience attending a live performance and an audience attending a streamed performance.

- To highlight differences in co-present and remote aspects in audience experience in a distributed performance.

Finally, we argue the case, hopefully of interest to both mainstream, non-mainstream theatres and companies involved in supportive technologies and infrastructure, that there is considerable benefit in 'giving a voice' to remote audiences, providing some sort of mechanism for feedback or interaction, during and after streamed performances.

This article is structured as follows. The next section introduces the theoretical foundations of our research, highlighting major theories that have been used for modelling the user experience. Next, we discuss the related work, contextualizing the application domain and the problem space. Section 4 describes in detail the two field trials that provided the results to allow us to identify cohesion and intensity as metrics for evaluating audience experience of networked performances. The next two sections provide details about the followed methodology and analyse the results, respectively. Finally, a discussion concludes the article.

\section{Theoretical considerations: orchestration of emotions and cohesion}

Hewlett Packard, the technology company, in collaboration with DreamWorks, the animation company, developed the first telepresence studio, called Halo. The Halo studios were technically well equipped featuring broadcast quality cameras and microphones, a private global broadband network, large plasma displays and soundproofed studios. Equally important, the studios were designed with film-set discipline in mind. Much attention was given to (front, side and back) lighting, audio quality and volume and the positioning of the cameras at three meters distance from the participants (above the screens) to mimic eye gaze. In addition, the rooms mirrored each other in layout of furniture and colour, giving the video conferencing participants a feeling that they occupied the same environment; an optimal feeling of telepresence $[25,26]$. Even though the round-trip delay time (RTT) was somewhere between 600-750 msec, depending on geographical distance, participants rarely noticed the delay. How can such findings be explained? One way of looking at this is through the lens of recent theories around the 'connected brain'.

Chartrand and Bargh [15] coin the notion of the 'Chameleon Effect' describing how conversational partners have a tendency to mimic one another. Moreover, we can see a potential underlying imitation system, that of the mirror neuron. This system, present within the pre-motor and inferior parietal cortices, contains neurons that activate not only when an action is performed but also when it is perceived. In fact, it is not just overt actions that causes activation in this system, facial emotions and hand actions [38] as well as speech [23] have also been shown to have overlapping areas of activation for action and perception and research in other domains are reporting similar findings. This in turn has provided evidence in favour of motor-based theories of comprehension in a number of domains, particularly speech where it has been hypothesized that the mirror neuron system may represent the network from which speech evolved [56]. 
The role of empathy has found to be both a facilitator of the chameleon effect and a predictor of the strength of mirror neuron activation in response to facial expressions [29] as well as sounds [24]. In telepresence research too, it has been shown that those with higher empathy ratings, as shown by self-report questionnaires, experience greater sensations of copresence [59]. If we assume that co-presence is associated with empathy, which in turn is a product of mirror neuron activation and mimicry, then it seems that those media that support a richer degree of sensory information (telepresence) help to create not only a sense of being there across the digital divide but also facilitate a degree of grounding [16] and comprehension. Thus, we argue that our findings can be interpreted as an indication that telepresence systems offer better facilitation to those mechanisms relating to the mirror neuron system and mimicry in comparison with lower quality systems, such as 1990's videoconferencing systems or personal computer based ones such as Skype.

Wilson and Wilson's account of a neural conversational turn taking mechanism [74] could provide further explanatory power.

In face-to-face communication, when someone is speaking, a listener will anticipate with minute precision when a conversational turn is ending, implying an entrainment of timing between participants in the conversation. This suggests some form of cyclic patterning, an involvement of endogenous oscillators in the human brain, which are populations of neurons that collectively show periodicity serving timing-related activity. Brain-based oscillators show properties of what are called relaxation oscillators (in contrast to harmonic oscillators) and are susceptible to outside influence only during one phase of their cycle and therefore, are highly stable, robust, and predictable in their timing properties.

Wilson \& Wilson explain that there is a close link between this fine-grained high frequency oscillation and the rhythmic production of phonemes. However, speech-rate, syllable production, which occurs at a larger time scale, seems less rhythmic. This is explained by another known phenomenon where lower frequency (more irregular) oscillators fine tune stable higher frequency oscillation. In this way, features of communication, whether fine- or course-grained, all play their role and work in concert.

In addition, Shockley et al. [63] point out the importance of, and effect on, cooperative conversation of body posture and sway. Nodding head movements and (hand and arm) gestures are well recognized as being an integral part of (lively) conversations. Breathing is another one of those lower frequency and coarser oscillators that helps with smooth turn taking in conversation. Failure to coordinate breathing around a turn transition is associated with simultaneous starts of speech [42].

Thus, we argue that the overall design of the Halo studios (identical rooms, soundproofing, good quality audio, lighting and superior image quality) is conducive to perceiving facial and body language. We suggest that this permits the activation patterns of participants' conversational neural oscillators to become entrained as well as supporting the chameleon effect (through appropriately firing mirror neurons). This enhances the perceived co-presence of remotely located participants, and may help negate the effects of the delay. It appears that providing a life-like conversational experience, such as with Halo, could mitigate some of the problems that were observed with mediated communication of a lower quality.

We would like to suggest, or, at least start an academic discussion through the current paper, that we can extrapolate this theoretical perspective from telepresence in high quality video conferencing to the realm of co-present and remote audience responses. In staging a performance, much attention is given to drawing an audience in. Orchestrating lighting, audio reproduction, set design, the artistic direction and performers immerse us in an out-of-the- 
ordinary experience, often referred to as suspending disbelief, involving all our senses and affecting our physiology [37, 70]. If, as Brown and Novak suggest [11], Mirror Neuron Theory is relevant to the theatre experience, then this most likely will involve the pre-motor cortex [57], the effects of facial language on the brain [23] as well as areas of the brain involved in language processing [74].

In addition to the involvement of the pre-motor cortex, there are suggestions that an area located 'deeper' in the brain, the so-called pain-matrix, is also involved in feeling empathy [28]. There may be truth in the old cliché: "I feel your pain".

In a way the audience presents itself as a metaphorical organ of emotions 'played' by the performance (the sum total of performers, set design, direction etc.), involving a plethora of psychological, neurological and physiological mechanisms. When, in a performance, all those mechanisms work in concert, we can say the performance is a highly cohesive one. Verbal, facial and body language of performers have the potential to cause an audience to resonate and empathise with the hero/heroine or be abhorred by the villain, sometimes causing truly visceral experiences.

Remote aspects of a performance may be experienced less intensely, e.g. the projected images originating from a remote location are likely to be less sharp than what a copresent audience sees (with their own eyes) in the theatre where the action takes place. However, we hypothesise that the closer all the different aspects of audience experience work in concert (the performance as a whole) the more cohesive a (co-present and remote-) audience experience is.

In the current paper we distinguish between intensity and cohesion of the audience experience. These two concepts are operationalized as follows:

- The intensity of the response simply relates to how high or how low questionnaire items pertaining to co-present and remote aspects of the performance were rated;

- Cohesion relates to how closely questionnaire items were correlated.

Of course these operationalizations may well seem simplistic (or even circular) and will depend on the type of questions we ask. However, we feel it is worthwhile to take quantitative audience analysis a step further; eventually trying to link the audience experience to neurological correlates.

\section{Related work}

This section revises both the different types of networked performances we have studied (streamed and distributed performances), and previous work on how to quantify audience experience. The application areas are studied in detail to provide the reader a better understanding about what we consider to be networked performances. We conclude this section with an overview of bringing users to the performance, as the next logical step of quantifying their experience.

\subsection{Quantitative audience evaluations of mediated performances}

Quantifying the audience experience is a good tool to measure impact of mediated performances, but how well researched is the field of audience evaluations in mediated performance? 
How sophisticated is the use of quantitative methods in this area? Angela Shrader [62] succinctly captures it in the opening sentence of her abstract:

"The filming of live theatrical events has grown in popularity in the current age of technology, but research in the field of audience perception of this practice is scarce."(Shrader, [62]).

Martin Barker is one of the trailblazers in audience research [4]. However, his forte is qualitative research. When evaluating the audience response to streamed live performances, he does mention his quantitative efforts, using five point (Likert) scales [41]. However, the analysis is restricted to listing percentages (e.g. Table 3.2 on page 29 of [5]) accompanied by simple bar-charts (page 31). None of these data are analysed using even the simplest of statistics, e.g. a Chi Squared analysis, to determine statistically significant differences between observed and expected frequencies.

Shrader [62] compares the audience response to a live performance of the production of The Odd Couple (by Neil Simon) with that of the recording of the final dress rehearsal, i.e. without a live audience. She uses a modified version of Boerner, Jobst and Wiemann's [9, 10] Likert scale questionnaire, resulting in scoring on three factors: emotional, cognitive and communicative responses. The quantitative results were complemented with quotes from a focus group. The results clearly show that the live experience was "more cognitive and communicatively effective". Although the mean for the emotional element was higher in the live condition than the remote (recorded) condition, due to a wide spread of responses in the recorded performance condition this difference did not reach significance. Strictly speaking, Likert scales only warrant ordinal data analysis, but Shrader applies the more powerful (ratio scale) analysis of variance (ANOVA). In this she is not alone. An examination of the CHI 2009 proceedings shows that $45.6 \%$ of all published articles use self-report Likert scales. $80.6 \%$ use ratio scale data analysis (ANOVA, $t$-test) and only $8.3 \%$ use ordinal or nominal data analysis [33].

Shrader does not analyse the responses to each question separately, but trusts the categorisation of Boerner, i.e. trusts that the various questions load on three (and only three) factors: cognitive, communicative and emotional. There is a distinct possibility that statistical analysis of the 'emotional' questions might have resulted in some significant differences between the live and recorded conditions; the devil is often in the detail.

Using a four point scale and the so-called Q-methodology, Vladica and Davis [69] evaluate the remote audience response to streamed theatre and opera performances. They discern four types of audience viewpoints: avant-garde, worthwhile, grateful and classical audience members. Each of these viewpoints are characterised by different scores on eight dimensions, aesthetics, efficiency, esteem, ethics, excellence, play, spirituality and status, visualised in a 'spider web' graphic. Although description of the Q-methodology is not easy to follow, one of the conclusions is that: "The novelty of live broadcast in cinema is an important draw." The avant-garde segment in particular considered this as the emergence of a new art form. Oddly enough, in our sample, it is the older (classical) theatre-goer that is more likely to attend a NTlive performance.

More akin to our approach is the detailed work of Brown and Novak [11]; assessing the intrinsic impacts of a live performance. As such, no comparisons are made with mediated performances. The emphasis is on the very nature of the theatre experience, evaluating the preand post-performance experience, an area which we explored using Galvanic Skin Response audience sensing complementing self-report pre- and post-performance questionnaires [70]. 
Brown and Novak [11] discern six indices of theatre experience under the headings of 'Captivation', 'Intellectual Stimulation', 'Emotional Response', 'Spiritual Value', 'Aesthetic Growth' and 'Social Bonding'. In their article they provide in-depth descriptions of these indices, recommended reading indeed, but for the purposes of the current paper, which focuses on method and analysis, we are interested primarily in the type of scale they use and their more advanced statistical analyses. Participants were instructed to fill out a five point Likert scale. They display results of a (presumably ratio scale) cluster analysis; their graph looks very much like the ones SPSS (Statistical Package for the Social Sciences) produces, similar to Multi Dimensional Scaling or Factor Analysis. However, Brown and Novak only mention "A variety of correlation and regression analyses were conducted to expose the relationships." It is not entirely clear which relationships between items were exposed.

Lin and Williams [40] compare a live opera production with one screened on five 'digital walls' but do not find any significant differences. We suspect that the lack of consistent, as well as a lack of sensitive, measurement might have been the reason for not finding differences. In addition to a demographic question, there were seven questions. Two questions asked about attending musical events in general using a four point ordinal format. Of the remaining five questions probing the audience experience, three questions were in a yes/no format, one question probed different aspects of the performance using a four point ordinal format and one question used seven alternatives in essence in a nominal format. The questionnaire would have benefited from the use of a more consistent format, even if that had been a five point Likert scale.

Lastly, we would like to mention an elegant and insightful study by Corness, Carlson and Schiphorst [18] describing a phenomenological method to research audience empathy in mediated performance. Although purely qualitative, the research results in an interesting model of remote audience reaction "along three separate but interdependent components of awareness: contextual, interpersonal and physical". These authors are also the first to mention Mirror Neuron theory [57] as an important theoretical consideration in this field. Their study does not concern a comparison between a co-present and remote audience, but one might imagine that a co-present audience experience will result in a higher contextual, interpersonal and physical awareness than that of a remote audience.

To summarise then, comparing co-present and remote audiences in streamed performances is still 'sparse' or 'scarce' (Shrader, [62]) indeed. In addition quantitative studies are even rarer; they are marred by the use of a diverse set of (often unnecessarily restrictive) methods and suffer from inappropriate and poor analyses, even though more sensitive methods and more sophisticated ways of analysis and interpretation have been available for decades.

Although there is considerable overlap with the audience research literature, our approach is primarily informed by our previous research into telepresence in video conferencing [26], is mainly quantitative, and consists of simple questions using a style of questionnaire originating from the food industry aimed at eliciting immediate responses. We are less interested in the rather heterogeneous collection of higher level constructs, such as Boerner and colleagues [9, 10], Vladica and Davis [69] and Brown and Novak [11] have proposed. Instead we analyse questions separately and we use advanced cluster analysis, Multi Dimensional Scaling [75], with an adapted variation of the concept of homogeneity (Kline, [34: page 12]): "The average correlation among items". We outline a quantitative method of data collection and analysis, in the hope that other researchers might see value in applying these. 


\subsection{Distributed performances}

This subsection provides sufficient examples of distributed performances in order to create a common understanding of one of the application areas we are focusing on.

Through the ages, performance artists have creatively made use of physical and, more recently, digital illusionary tools:

"There is nothing in cyberspace and the screened technologies of the virtual that has not been already performed on the stage. The theatre has always been virtual, a space of illusory immediacy" (Causey, [13]: p 383-394].

To illustrate how old such illusionary tools can be, we mention Giambattista della Porta, a 16th Century Neapolitan scholar. In his 1584 work Magia Naturalis (Natural Magic) he describes an illusion, entitled "How we may see in a Chamber things that are not", i.e. creating an illusion in which it seems that objects appear and disappear [54]:

"Let there be a chamber wherein no other light comes, unless by the door or window where the spectator looks in. Let the whole window be of glass. Let one part be polished, that there may be a looking-glass on both sides, whence the spectator must look in. Let pictures be set over against this window, marble statues and suchlike. For what is without will seem to be within, and what is behind the spectator's back, he will think to be in the middle of the house, as far from the glass inward, as they stand from it outwardly, and clearly and certainly, that he will think he sees nothing but truth."

This technique is better known as the Pepper's Ghost effect (Fig. 1) named after John Henry Pepper who developed Porta's illusion further, taking advantage of developments in electric stage lighting in the 19th Century [52].

Taking this whistle stop tour to the 21st Century, using acrylic film and video conferencing technology, Musion [46] creates 'holographic illusions' e.g. Gorillaz' performance at MTV Europe awards [47]. It is not unreasonable to assume that these types of smoke and mirror illusions date back centuries.

Birringer [8] and Dixon [21] provide comprehensive overviews of how artists have exploited (digital) technology to enhance performances. Experimenting in the arena of multisensory communication, Stahl Stenslie [66] has developed haptic communication as a tool in (distributed) performance art [65].

Where video applications are concerned, theatre pieces have made use of wearable cameras [66] and virtual environments have been populated using motion capture, performing avatars

Fig. 1 Pepper's ghost. Image taken from [17]

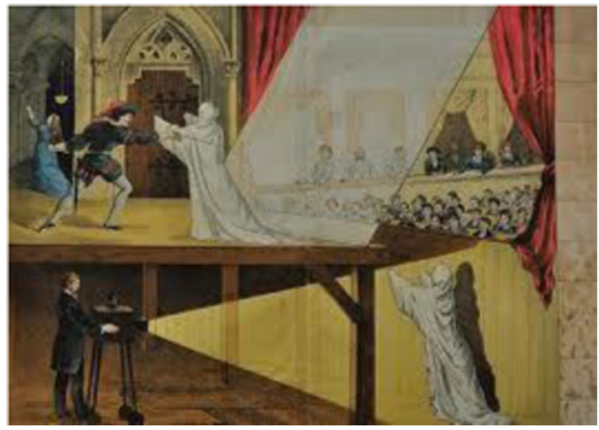


and thespian robots [6]. Here, we narrow down the scope to the use of interactive videoconferencing technologies applied to the performance space.

In the last three decades, videoconferencing technology has extended the performance artist's palette, creating a new genre of distributed performance art, often using bespoke and expensive hard- and software. Carefully designed lighting has been instrumental in creating an atmosphere that draws audiences in, enhancing a feeling of telepresence, i.e. a feeling of being there across a virtual divide. In designing telepresence (high end videoconferencing) studios, a collaboration between Hewlett Packard and Dreamworks, we also found that film-set discipline, in particular lighting, played a crucial role in optimising telepresence [25].

As early as 1992, Paul Sermon [61] (see Fig. 2) devised Telematic Dreaming, an intimate interactive work, featuring two double beds in separate rooms linked via an audio and video connection. Using multiple cameras, projection surfaces and chroma key blankets (not a million miles from the Pepper's Ghost illusion), this allowed the virtual sharing of beds. Pre-recorded video footage was mixed into the live projections. Visitors to the installation were free to interact with the performers. Most of the time the intimacy engendered trust but the virtual had the potential to shock as much as the physical as on one occasion:

"Someone took out a knife. I felt the predictable shiver; [it] set off alarm bells in my mind." (Kozel, [35])

Lisa Naugle [49] introduced the term 'distributed choreography' for collaborations between geographically distributed dance-studios across six universities in the USA using a broadband network connection. The live choreography was complemented with additional imagery and sound. The production highlighted logistical and technical problems: coordinating the geographical time differences, delays inherent to video conferencing, managing the choreography cues (knowing when to begin and when to end a section) and, as we shall highlight later, the inability of a remote audience to provide feedback during and after the performance.

Similarly, Ivani Santana [58] has been working extensively in the field of Networked Dance Performance connecting dance studios across the world in Brazil, Chile, Germany, France, Spain and the USA [53].

With the emergence of pervasive low cost videoconferencing systems, such as Skype or Hangouts, there has been an increase in mediated performances; we mention a couple:

Skype Duet was a distributed live performance between New York and Berlin [67]. Pushing the boundaries of interactivity, Dimanche Rouge by Panoply involved actors and dancers accompanied
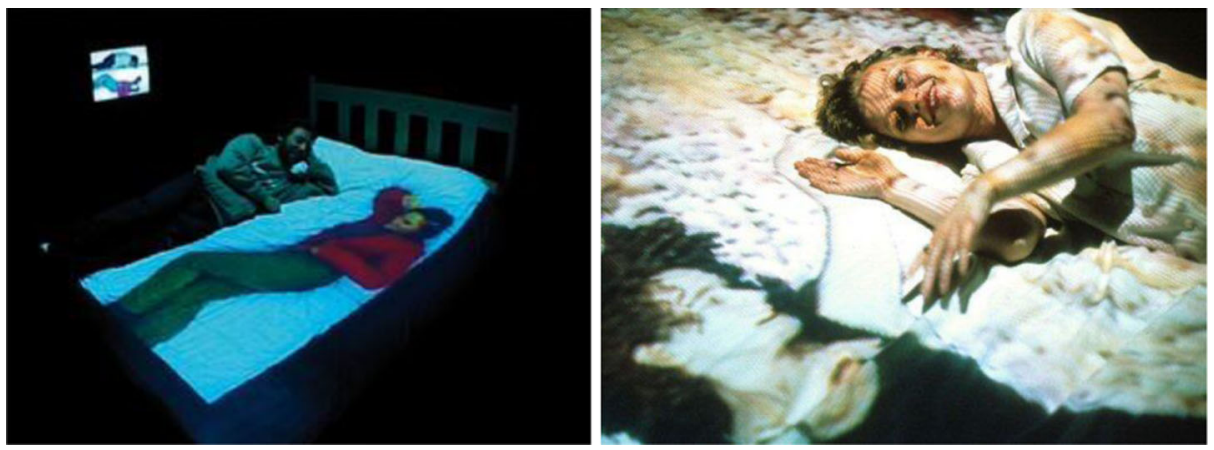

Fig. 2 Telematic dreaming, video available from Paul Sermon [61]. Images taken from [36] (left) and [51] (right) 
by pre-recorded video and other multi-media work streamed live between Paris and New York providing opportunities to distributed audiences to interact, give feedback and even co-create [50].

Cinzia Cremona describes this proliferation of on-stage screen interaction as:

"Skype communication and video-performance have been converging into a set of art practices that adopts the screen as a relational device" (Cremona, [19]).

For completeness, we mention that audience participation, often using simple mobile phone messaging, has been an integral part of a number of interactive theatre performances.

"Research conducted at the intersection of live art and digital technologies constitutes a blossoming area within HCI (Human Computer Interaction). This extensive and variegated body of work reflects the pervasiveness of technology in the context of artistic and cultural experiences while bringing to the fore a number of emergent issues such as people's participation in interactive installations and performances." (Cerrato-Pargman et al., [14]).

Teresa Cerrato-Pargman and colleagues [14] indeed, in their very first paragraph, reel off 15 references, indicating there is a considerable body of work in this area; another addition to the emerging palette of (occasionally distributed) performance art. This might provide additional methods to be used in evaluating mediated performances. For now, however, we feel that an in-depth review would detract somewhat from our focus on quantitative research methods evaluating a passive, rather than a participating, audience response.

\subsection{Mainstream streamers}

This subsection provides sufficient examples of streamed performances in order to create a common understanding of one of the application areas we are focusing on. The phenomenon of mainstream theatres streaming their productions live to remote audiences has been described in detail. Martin Barker [5] reviews the remarkable rise of, what he terms, 'livecasting' and its antecedents:

"On the last weekend of 2006, the New York Metropolitan Opera launched a new initiative. Captured by up to a dozen high-definition digital cameras in front of more than 3,000 attendees, a live performance of Mozart's The Magic Flute was beamed to 100 digitally equipped cinemas in the USA, the UK, Canada, Norway - and, with a delay, Japan.” (Barker, [5]).

The driver for the Metropolitan Opera was an economic one: dwindling ticket sales and the average age of the audience being 65 , the live opera spectator seemed a dying breed. Somehow this and following productions turned the fortunes of the New York opera around as the value proposition for live streamed performances was put forward as: "a close-up front of house feel".

There have been plenty of precursors (sports, rock concerts etc.), a variety of live broadcast events streamed to relatively large viewing locations, e.g. watching a football match live in the pub. In the world of theatre, the National Theatre soon followed suit:

"In the UK the first big player to join the parade in a determined way was the National

Theatre, through a spin-off arm, NT Live in 2009.” (Barker, [5])

Anecdotal evidence, witnessed at a local cinema after a particular NT Live [48] streaming event, suggests that the brave new world vision of live casting, having a front of house seat, in practice comes down to the more pragmatic and mundane: 
"We live in the sticks here and this is the only way we are able to see a National Theatre production."

[A visitor to an NT live event at a Falmouth Cinema]

Similarly, the difference between a live and a streamed performance has been likened to:

"The difference between gloss and matt paint."

[Another visitor to an NT live event at a Falmouth Cinema]

Streaming live performances and showing recordings of live performances in cinemas, so called encores, is generally seen as a commercial success. They strengthen the brand and widen the reach of the mainstream streamers worldwide. NT Live continues to increase its UK and international coverage [3, 60]. The performances transmitted are of special performances where the cameras are allowed more freedom to get edge of stage shots and close ups and the audience are asked to tolerate the intrusion. This type of coverage is described by Nicholas Hytner Artistic Director of the National Theatre, as akin to the coverage of live sports events [12] and is in contrast to the traditional screening of theatre performances that relied on static cameras filming so as to be unobtrusive and not detract from the experience of the theatre-goers.

However, there are currently a number of technological restrictions to the NT live streaming events as these require satellite reception and high-end (expensive) projectors (and audio reproduction) at the remote locations. In addition, capturing a live performance using a professional camera crew and production team is costly. Such costs are prohibitive for low budget performing arts organizations to follow suit. Part of our research explores how live streaming technology can be replicated at a lower cost by low budget theatre companies.

\subsection{The deafening silence of the remote audience}

Other than a camera crew getting in the line of sight, it seems that an audience attending a live performance that is streamed to remote venues is barely aware of there being remote audiences. During and after live-streaming, there are no possibilities for remote audiences to feedback to the theatre of origin; they are effectively rendered invisible, in sharp contrast to the role of a co-present audience; to quote Lisa Naugle [49] when contrasting a remote with a copresent audience:

"Having a clearly located audience, a 'front' to play to, provides an energy, a lift performers often get from an audience" (Naugle, [49]).

Creating provisions for remote audience interaction may help to create a sense of (remote and co-present) audience community and contribute to the audience excitement (across distributed locations) that is brought about during and after a live and interactive distributed theatre performance. The consequences for adding interactive home viewing to this paradigm are as yet unforeseen.

In short, current (mainstream) distributed performance solutions have limitations: they are bespoke and expensive; there is no real-time remote audience feedback, either from remote to co-present audience or between remote audiences in different locations.

Technology development addressing these limitations may help to pave the way for a commercially viable model, affecting the way distributed theatre is written, staged, 
performed and delivered; giving rise to the emergence of new genres of theatre production between connected locations. A whole host of newly developed integrated technologies will need to be in place for this to occur, e.g. high quality broadband audio-visual communication, media composition, 3D stage-sensing and audience response visualization and/or sonification.

We believe that the time is right for an investment into bundling such technologies to enhance what Philip Auslander [2] calls the 'liveness' of a mediated performance, the excitement of synchronicity of (and for) remote and co-present audiences alike; asynchronous communication (messaging) simply is insufficient. A good understanding of the co-present and remote audience experience will be essential to help steer such a technology agenda.

Having sketched out the wider landscape, the wider context of our research, we will now return to the two field trials we conducted. In both, we worked for well over a year with the Cornwall based but nationally touring Miracle Theatre Company [43].

\section{Field trials}

\subsection{Field trial 1: Co-present audience vs. Encore (waiting for Godot, September 2013)}

The main research question of the first field trial was: How do a co-present and remote audience experiences compare when enabling a low budget theatre company to stream their live performance?

The performance was captured using four broadcast quality video cameras and an array of shotgun microphones. This was edited live and streamed to three geographically distributed locations.

We used commercially available streaming technology over IP which at that time, 2013, was the state of the art (Sonic Foundry's Mediasite [64]), as it utilises Microsoft's Smooth Streaming technology, which adjusts the quality of the live stream based on the viewer's available bandwidth. If bandwidth is high, then a viewer receives a High Definition (HD, a resolution of $1280 * 720 \mathrm{p}$ at $4.5 \mathrm{Mbit} / \mathrm{Sec}$ ) stream; if the bandwidth is lower, the player adjust to one of the seven available streams to optimise resolution and reduce buffering. In other words, the system optimises the quality of the viewing experience based on available bandwidth.

As is befitting for a Beckett play (Fig. 3) with its slow moving action and strong emphasis on language, the live editing consisted mainly of slow transitions between wide shots with an occasional close-up.

Thus, Miracle Theatre's production of Samuel Beckett's 'Waiting for Godot' was streamed live from Falmouth University Performance Centre to three geographically distributed locations: Plymouth, Manchester, and St Agnes, a small town in Cornwall, UK.

Here we compare the audience response of the live performance with that of the encore of the production.

\subsection{Field trial 2: distributed audiences (the distributed tempest, September 2014)}

The second field trial evaluated the audience experience of a distributed performance; an adapted version of Miracle Theatre's stage production of Shakespeare's The Tempest, 


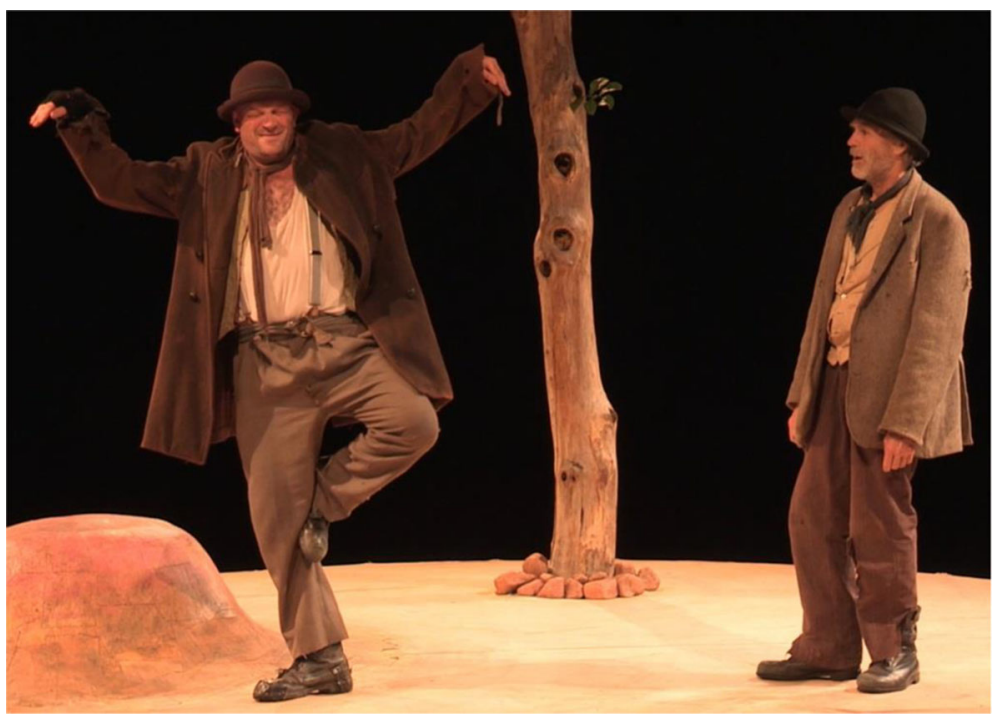

Fig. 3 Waiting for Godot by miracle theatre. Screenshot from footage captured by Dogbite studios falmouth [22], with kind permission

using two Internet connected theatre spaces, each with its own audience. More setup details and a summary of the plot can be found in [32]. The Tempest is set on an island. Some of the action was played out in one theatre location (set on one part of the island) and some of the action in the second theatre location (set on another part of the island), with actors communicating via screens, which formed an integral part of the set-design, and wireless microphones, which were positioned close to the actors' mouths, to prevent audio-feedback (howling).

The enabling technologies for this second field trial have been reported elsewhere [32, 72, 73].

Specifically, we have developed a script-based approach to enable the dynamic control of screen contents and pan/tilt/zoom (PTZ) cameras. Screens adaptively showed remote video streams, compositions of multiple streams, and even layouts that combined live with recorded contents. A single operator was sufficient to synchronize the execution of the production script (predefined commands to the technical infrastructure according to the director's specifications) with the actors' pace of the play.

Figure 4, for instance shows a zoomed-in shot of the remote actor playing Prospero in one location addressing the actors in the other location.

The production made use of a number of cinematographic techniques. In addition to the camera scripting, there were markers on stage to mimic eye gaze between actors on each side of the digital divide (i.e. between the two locations). The role of Ariel required two actors, one in each location, who apparently (and seamlessly) moved between the two locations. As such the filmic 'treatment' used in The Distributed Tempest (see video [44]) was more dynamic than was used in the streaming of Waiting for Godot.

The distributed performance was also streamed to a small number of homes. Studying this home audience was more exploratory in nature, as the home-viewers were either part of, or close to, the research team, and will not be described in-depth. 


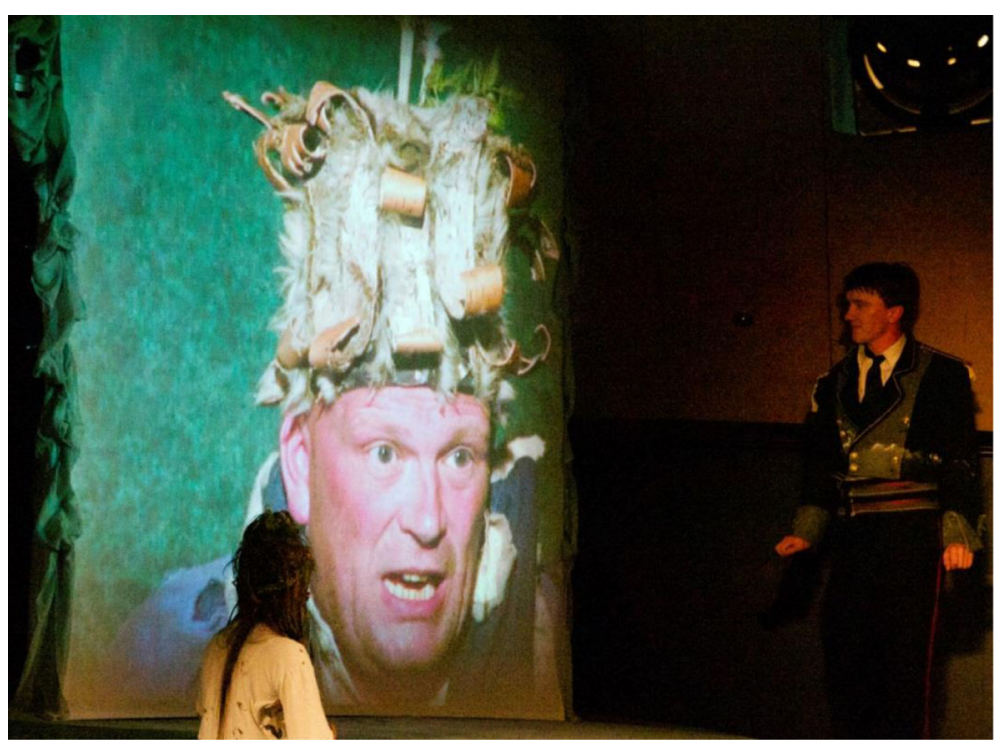

Fig. 4 The distributed tempest. Image used with kind permission JointEffort studios [30]

\section{Methodology}

\subsection{Graphic rating scales}

In both field trials audience members filled out a pen-and-paper survey in graphic rating scale format [68]. This type of scales, regularly used in the food industry, have a number of advantages over the prevalent five point scales [41]: cognitive interference is attenuated, they map on better to underlying experiences, the phrasing of the questions is simpler and they satisfy requirements for rating scale analysis [1], whereas Likert scales, at best, allow for ordinal data analysis [33]. An example of a graphic rating scale is shown below:

- How much did you enjoy the performance?

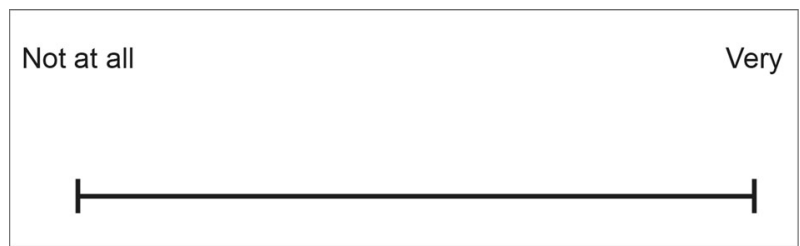

Participants were asked to make a mark on the line, which could include the extremes ('Not at all', on the left and 'Very' on the right). The questionnaires were distributed immediately after the performance. The scale measured $112 \mathrm{~mm}$ and the responses were measured using a ruler to $1 \mathrm{~mm}$ accurate. For dissemination purposes we scaled the responses down to a scale ranging from 0 (= Not at all) to 100 (= Very). 


\subsection{Field trial 1: co-present audience vs. encore (waiting for Godot)}

The participants of the co-present audience (September 2013, Performance Centre, Falmouth University, UK) consisted of 33 females and 26 males. There were no significant age differences between females and males thus the co-present sample totalled $N=59$ (mean age $=43.03, \mathrm{SD}=15.1$ ).

The encore audience consisted of a total of 34 females (mean age 40.85, SD $=18.8$ ) and 22 males (mean age 42.77, SD=20.45). Fourteen participants were at the Forum Alumni Auditorium in Exeter, 30 in Plymouth Barbican and 12 at the Driftwood Spars Pub in St Agnes, Cornwall. There were no significant age differences between females and males or between the three locations. In this respect the co-present and remote audiences were homogenous. Fourteen questions in graphic rating scale format probed the audience experience:

1. How much did you enjoy the performance?

2. How immersed were you in the performance?

3. How close did you feel to the actors in the play?

4. How clear was the story-line?

5. How close did you feel to the audience in the room with you?

6. How close did you feel to the audience where the live performance was?

7. How sad did you feel during the performance?

8. How often did you laugh during the performance?

9. How often did you smile during the performance?

10. How quickly did time seem to pass?

11. How loud did you clap at the end of the performance?

12. How strong was the urge to clap at the end of the performance?

13. How well could you see the play?

14. How well could you hear the play?

\subsection{Field trial 2: the distributed tempest audience}

Forty-seven participants filled out a survey. The mean age was 41.95 years $(\mathrm{SD}=16.01)$. There were 24 participants seated in one of the two locations (the Maritime Museum, 16 females, seven males); 16 participants were at the second location (the Doghouse, 10 females, five males). In addition, a further seven participants (four females, three males) moved in the interval from the Maritime Museum to the Doghouse, making this a total of 47 participants. Not all revealed their gender or age. Both locations were in Falmouth, Cornwall, UK. We had to adapt the questionnaire we used for Waiting for Godot to address issues specific to distributed rather than streamed performance. Nevertheless, there is overlap between the two questionnaires. We used eleven graphic rating scale questions:

1. How much did you enjoy the performance?

2. How immersed were you in the action that took place in the room where you were?

3. How immersed were you in the action that took place in the remote location?

4. How close did you feel to the actors in the room where you were?

5. How close did you feel to the actors in the remote location?

6. How close did you feel to the audience in the room where you were? 
7. How close did you feel to the audience in the remote location?

8. How well did the action flow between the two locations?

9. How well could you see the action in the remote location?

10. How well could you hear the actors in the remote location?

11. How loud did you clap at the end of the performance?

This was followed by two open questions asking what they did and did not like about the performance.

\subsection{Statistical analysis}

The questionnaire data were analysed and visualised by the first author using SPSS (Statistical Package for the Social Sciences, IBM) providing statistical descriptions; analysis of variance (ANOVA) was used to explore differences (there were no violations of the statistical model, i.e. all distributions were normal, kurtosis and skewness were well within the recommended -2 to +2 range); correlations and Multi Dimensional Scaling (MDS) [75] were used to analyse similarities. MDS is not often found in literature on human technology interaction, even though there are innovative ways to visualize MDS plots [39].

\section{Results}

\subsection{Co-present vs. encore audience (waiting for Godot)}

\subsubsection{Differences}

The bar-chart (Fig. 5) summarizes how the audience that attended the live performance, the copresent audience, of Waiting for Godot rated the various questions probing the audience experience, on a scale from 'not at all' (0) to 'very' (100) as solid bars accompanied by

Waiting for Godot:

Co-present Audience ( $\mathrm{N}=59$, solid bars) vs. Encore ( $\mathrm{N}=56$, transparent bars)

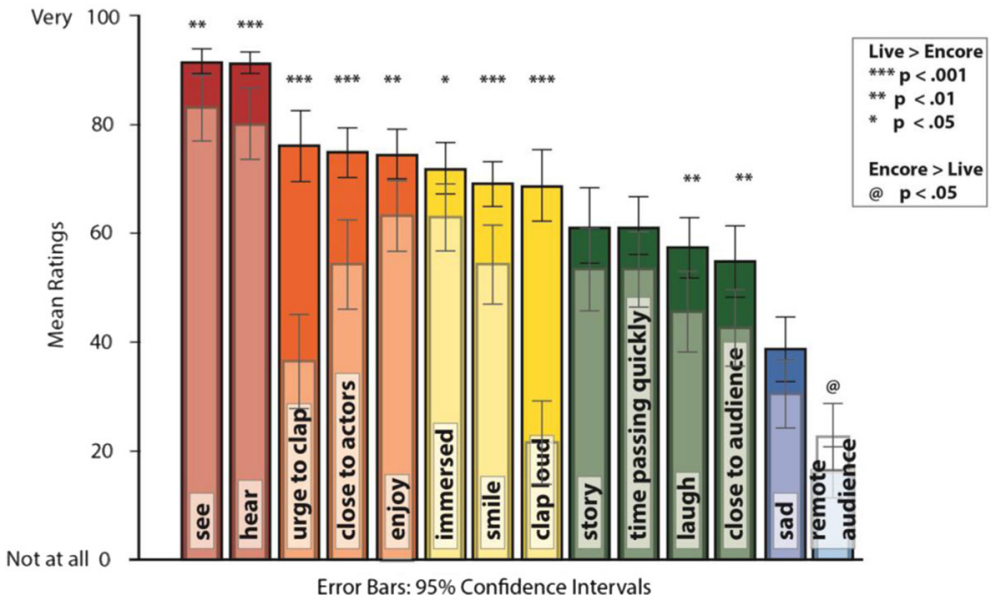

Fig. 5 Co-present vs. encore audience response 
$95 \%$ confidence intervals (the whiskers). The audience response to the encore is shown in transparent (as well as narrower) bars, also accompanied by the $95 \%$ confidence intervals.

Statistical analysis (a paired comparisons exercise) pointed to five distinct (i.e. significantly different) bands of ratings by the co-present audience.

We also show (above each bar) where we found significant differences between the copresent and encore audience experience. Asterisks, (***, $p<.001 ; * *, p<.01 ; *, p<.05)$ indicate significantly higher ratings for the co-present ratings and an ampersand (@, $p<.05$, last bar) indicates a significantly higher rating for the encore audience response.

The means and standard deviations (SD) for the co-present and the encore audiences are shown in Table 1 below. The column on the right in Table 1 shows where there were significant differences between the co-present and encore audiences.

High Ratings (Red bars. Mean =92): The co-present audience rated their ability to see and hear the play (no amplification was used in the theatre) very high and the encore audience, that heard the audio via loudspeakers, rated these significantly lower.

High-Mid Ratings (Orange bars. Means range from 75 to 76): The co-present audience reported a strong urge to clap (significantly higher than they rated how loud they actually clapped), felt very close to the actors and enjoyed themselves thoroughly. The encore audience rated these questions significantly lower, although enjoyment and immersion were still rated relatively high.

Mid Ratings (Yellow bars. Means range from 69 to 72): These were still ratings with means that were well above the $50 \%$ mark. The co-present audience was immersed in the performance; they clapped loud and smiled often. They smiled significantly more than they laughed. The encore audience experience was significantly lower in all these respects.

Low Mid Ratings (Green bars. Means range from 55 to 62): Although on average still above the $50 \%$ mark, the co-present audience rated their ability to follow the story line lower ("after all this was Beckett", some wrote), time didn't really drag on but did not pass that quickly, their laughter was less frequent than their smiles and they did not particularly feel close to the rest of the audience.

There were fewer differences with the encore audience for the low mid-range, i.e. no significant differences with how clear the story line was and how the passing of time was

Table 1 Waiting for Godot: co-present and encore audience

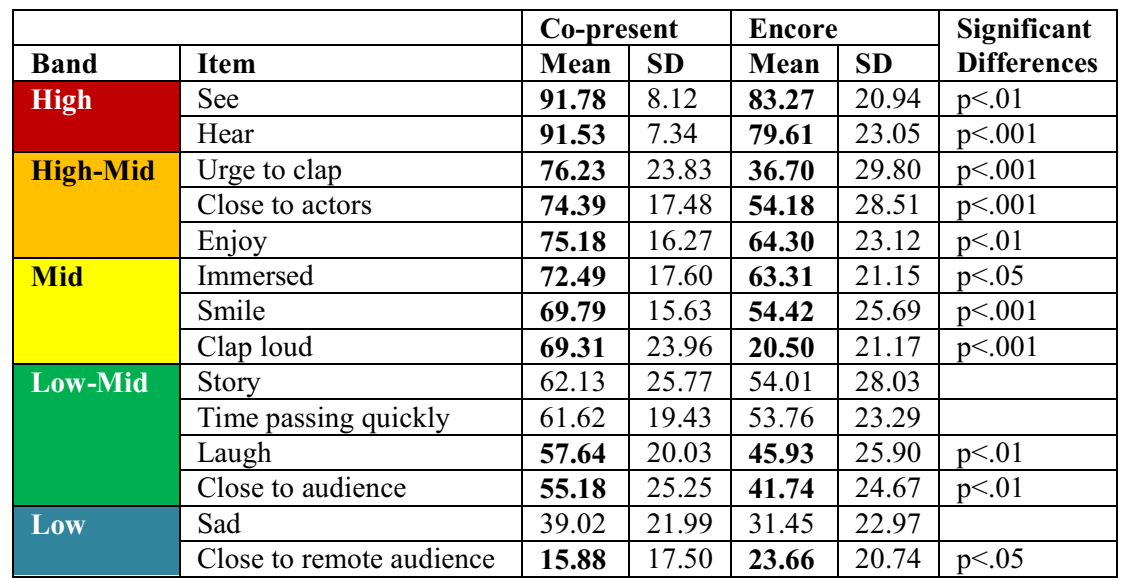


perceived, However in the encores the ratings were significantly lower for how often they laughed and how close they felt to their co-located audience (the people in the location where they watched the encore).

Low Ratings (Dark Blue, mean $=39$ and Light Blue, mean =16): Waiting for Godot did not make the co-present audience feel sad (overall) and significantly lower still were the ratings of how close they felt to the remote audience. The encore audience felt significantly closer to the remote audiences elsewhere (Exeter, Plymouth and St Agnes) than the audience at the live performance felt to the three locations where the live performance was originally streamed to.

\subsubsection{Similarities}

Differences in ratings only partially describe the live theatre (co-present) audience experience. MDS cluster analysis based on correlations (similarities) provided further insights (Fig. 6) visualising how the co-present audience variables inter-correlated. The size of the circles is determined by how many inter-correlations were statistically significant and the level of significance of the correlations. In the next section (The Distributed Tempest) we elaborate how we arrive at the size of the circles.

At the core of the co-present audience experience for the live performance of Waiting for Godot was how loud they clapped at the end. The applause correlated extremely high (signified by thick red lines, $p<=.001$ ) with the urge to clap, being immersed in the play, how close they felt to the actors, how much they enjoyed the performance, how quickly time seemed to pass, how often they smiled and laughed. In a way the applause seems to be the culmination, the catharsis, of the audience experience, where all those feelings during the performance of feeling close to the actors, being immersed, etc., find their way in a communal expression of appreciation. Thus, we consider the cluster made up of these variables as a

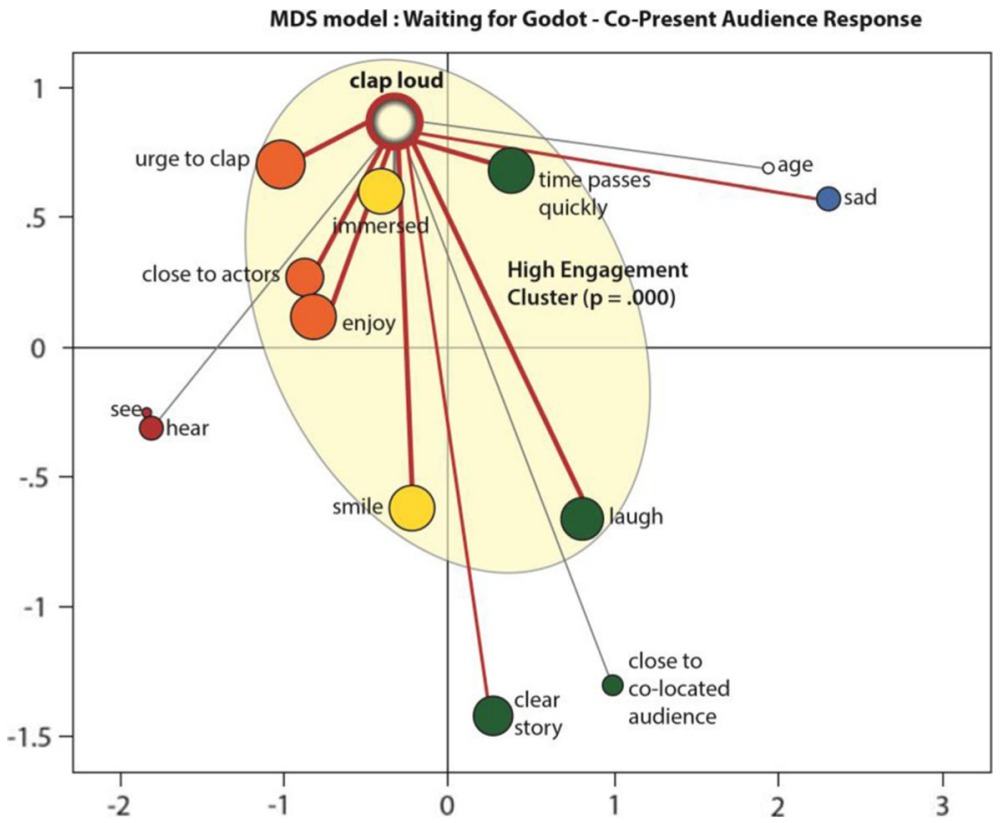

Fig. 6 MDS Co-Present audience response 
highly cohesive core of the Waiting for Godot experience. Moreover, 'clap loud' correlates significantly with all the other variables with the exception of 'seeing well'.

Two dimensional MDS plots feature X- and Y-axes. Invariably, we are questioned what these refer to, i.e. what do the $\mathrm{X}$-axis and Y-axis signify? In other studies, on totally different topics, we have found it useful to interpret the axes in a type of 'market research' style (almost like a dark art). Here we omitted doing that because the MDS plot for the co-present plot correlated so tightly (was highly cohesive) that really we were looking at one closely correlating 'blob' without clearly defined extremities (X- and Y-axis). As a consequence we have not interpreted the axes in the other MDS plots in this paper either.

Cluster analysis of the encore data (Fig. 7) revealed a more 'dispersed', less cohesive experience (fewer and less strong correlations; none reached $p=.000$ ) which revolved around smiling during the performance, an altogether more introvert experience.

\subsection{The distributed tempest}

\subsubsection{Differences}

Firstly we compared whether there were any differences in how the questions were answered between the 24 audience members in the first location, the seven audience members who moved from the first location to the second location and the 16 audience members who were in the second location. We found no significant differences and therefore we grouped the data originating from the total of 47 participants together.

The bar-chart (Fig. 8) summarizes the descriptive statistics. Here we follow a different rationale for colour coding the bars: the blue bars represent the more general, overall response of the audience, the red bars signify feelings of being close to the co-present action (in the

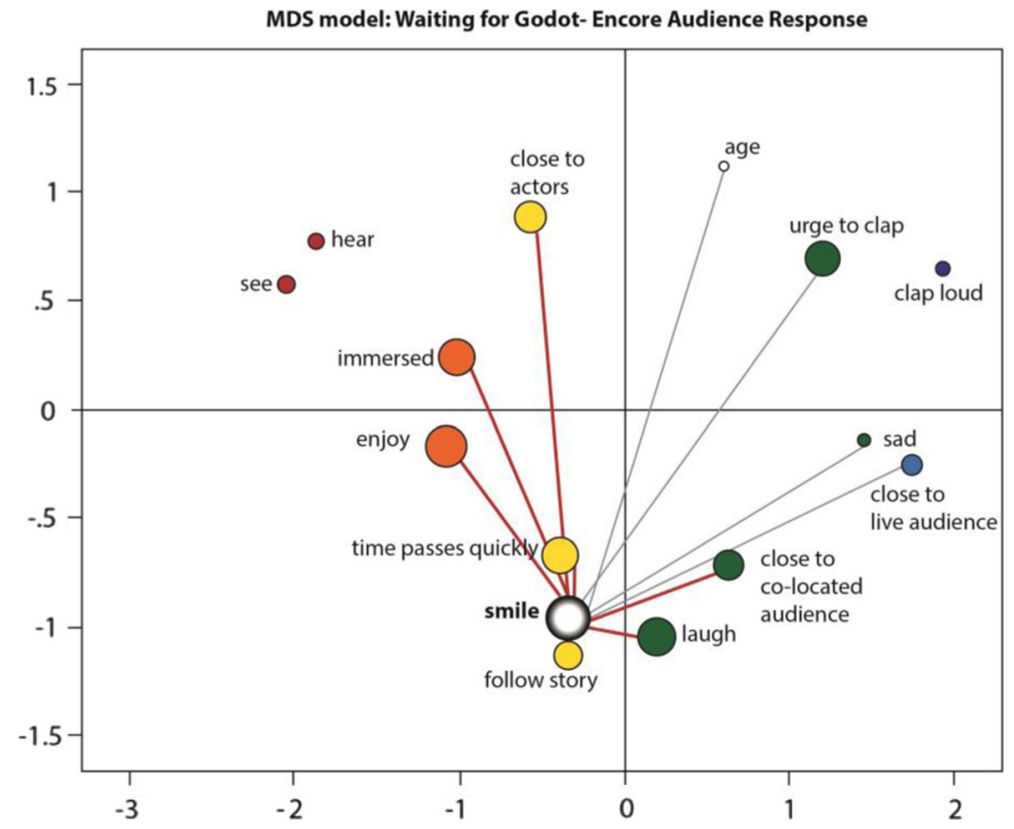

Fig. 7 MDS solution encore audience 


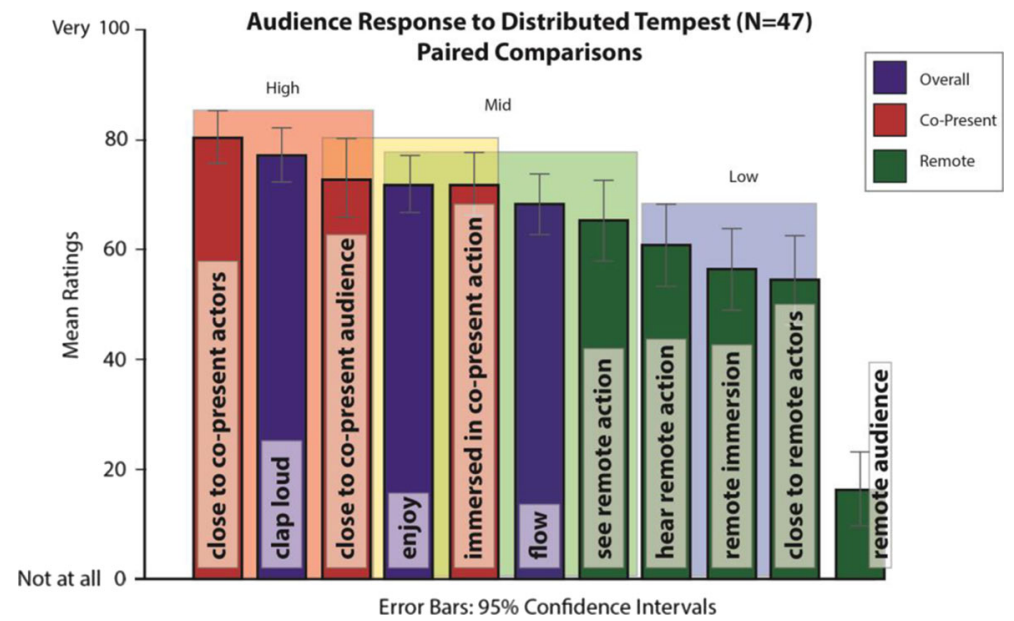

Fig. 8 Audience response for the distributed tempest

room the audience was in) and the green bars indicate feeling close to the remote action. It is clear from inspecting the graph that all the remote experience bars are on the right hand (the lower ratings) side of the bar-chart.

Using paired comparisons between all variable enabled us to delineate bands of high, medium and low ratings. The results were not always clear-cut and we see some overlaps for the medium ratings, which is why we group high mid and low mid ratings together. In addition Feeling close to the co-present audience takes an intermediary position between High and Medium ratings.

Table 2, below, shows the means and the standard deviations.

High Ratings (Means range from 74 to 81): The band of high ratings is made up of feeling close to the co-present actors, clapping loud at the end of the performance and feeling close to the co-present audience.

Table 2 The distributed tempest descriptive statistics

\begin{tabular}{|c|c|c|c|}
\hline Band & Item & Mean & $\mathrm{SD}$ \\
\hline \multirow[t]{3}{*}{ High } & Close to co-present actors & 80.66 & 15.27 \\
\hline & Clap loud & 77.72 & 15.93 \\
\hline & Close to co-present audience & 73.61 & 23.04 \\
\hline \multirow[t]{4}{*}{ Medium } & Enjoy & 71.86 & 16.65 \\
\hline & Immersed in co-present action & 72.36 & 18.59 \\
\hline & Flow between locations & 68.71 & 17.79 \\
\hline & See remote action & 64.76 & 24.49 \\
\hline \multirow[t]{3}{*}{ Low } & Hear remote action & 60.79 & 24.69 \\
\hline & Remote immersion & 55.93 & 24.95 \\
\hline & Close to remote actors & 52.50 & 27.25 \\
\hline Lowest & Close to remote audience & 15.78 & 21.60 \\
\hline
\end{tabular}


Medium Ratings (Means range from 65 to 74): A medium band consisted of enjoying the performance, being immersed in the co-present action, judging the flow of action between the two locations as good and being able to see the action well in the remote location.

Low Ratings (Means range from 53 to 65): Lower ratings (but still over the $50 \%$ mark) were given for being able to hear the remote action, being immersed in the remote action and feeling close to the remote actors.

Lowest ratings (Mean =16) were given for feeling close to the audience in the other location. This was to be expected as the main aim of the trial was to make the technology work and no effort was made to connect the distributed audiences, e.g. visually.

\subsubsection{Similarities}

Here we elaborate how we visualise similarities based on the matrix of correlations between questions. In particular we used the level of significance as a way to enhance the MDS plot that SPSS generates.

Below we show, as an example, the scatter plot (Fig. 9) for the correlation between Remote immersion and Feeling close to the remote actors, resulting in a highly significant correlation: $\mathrm{r}(\mathrm{df} 37)=.851, p=.000$. The plot shows in the bottom left participants who rated both questions low and in the top right participants who rated both questions high. The line through the data cloud signifies how strongly the two questions co-vary.

Remote immersion correlated significantly with nine other questions (Table 3). For pvalues $<=.001$ the arbitrary weight of ' 4 ' was assigned; to $p$-values $.001<p<=.01$ we assigned the weight ' 3 ', to p-values $.01<p<=.05$ a weight of ' 2 ' and to $p$-values $.05<$ $p<=.10$ a weight of ' 1 '. Thus Remote immersion received a total weight of ' 33 ' and the size of the circle was determined by dividing the total weight by the number of variables - $1(=11)$ in the MDS analysis. All correlations were positive and we assigned weights (reflected in the size

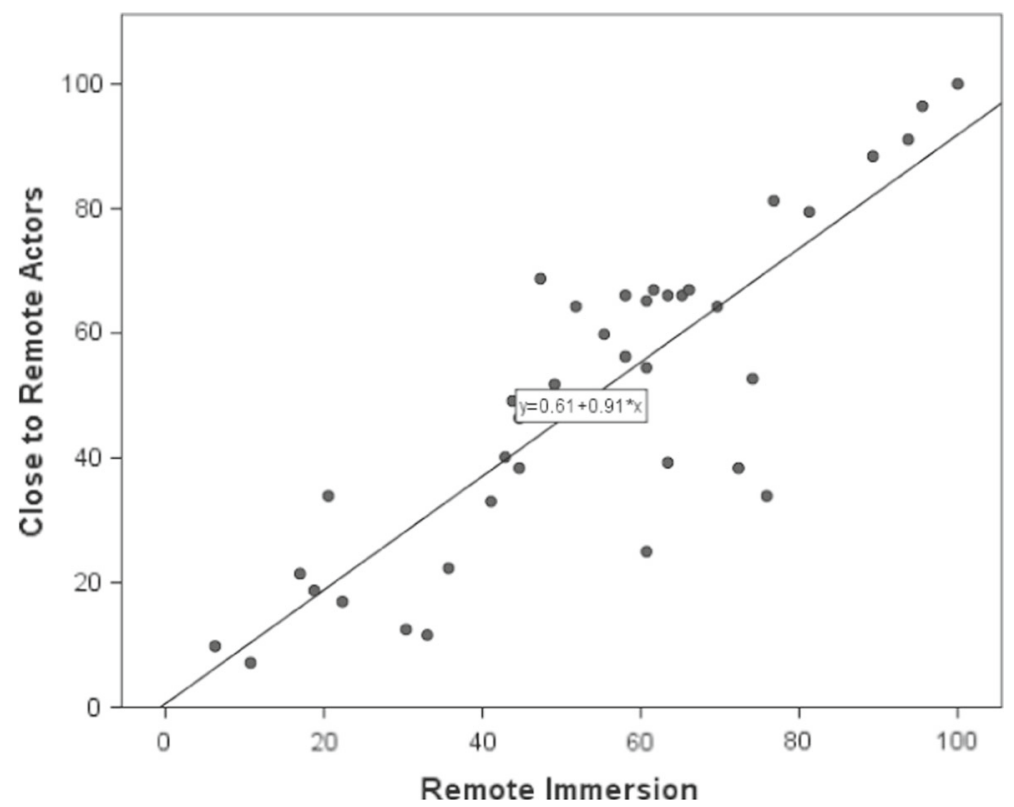

Fig. 9 Scatter plot: remote immersion vs. feeling close to remote actors 
Table 3 Significant correlations for remote immersion

\begin{tabular}{llr}
\hline Item & $p$-value & Weight \\
\hline Enjoy & $\mathbf{. 0 0 0}$ & 4 \\
Close to remote actors & $\mathbf{. 0 0 0}$ & 4 \\
Flow between locations & $\mathbf{. 0 0 0}$ & 4 \\
See remote action & $\mathbf{. 0 0 0}$ & 4 \\
Hear remote action & $\mathbf{. 0 0 1}$ & 4 \\
Clap loud & $\mathbf{. 0 0 1}$ & 4 \\
Close to co-present actors & $\mathbf{. 0 0 6}$ & 3 \\
Close to co-present audience & $\mathbf{. 0 1 7}$ & 2 \\
\hline
\end{tabular}

of the circles in Fig. 10) in an identical manner to all other variables. As there were no significant correlations for feeling close to the remote audience, this variable was omitted from the MDS analysis.

For completeness, we show the significant $p$-values for the entire correlation matrix (Table 4) below and the weights given to them. To recap, the variables were:

\section{Age}

Enjoy: How much did you enjoy the performance?

C-imm: How immersed were you in the action that took place in the room where you were?

R-imm: How immersed were you in the action that took place in the remote location?

C-actors: How close did you feel to the actors in the room where you were?

R-actors: How close did you feel to the actors in the remote location?

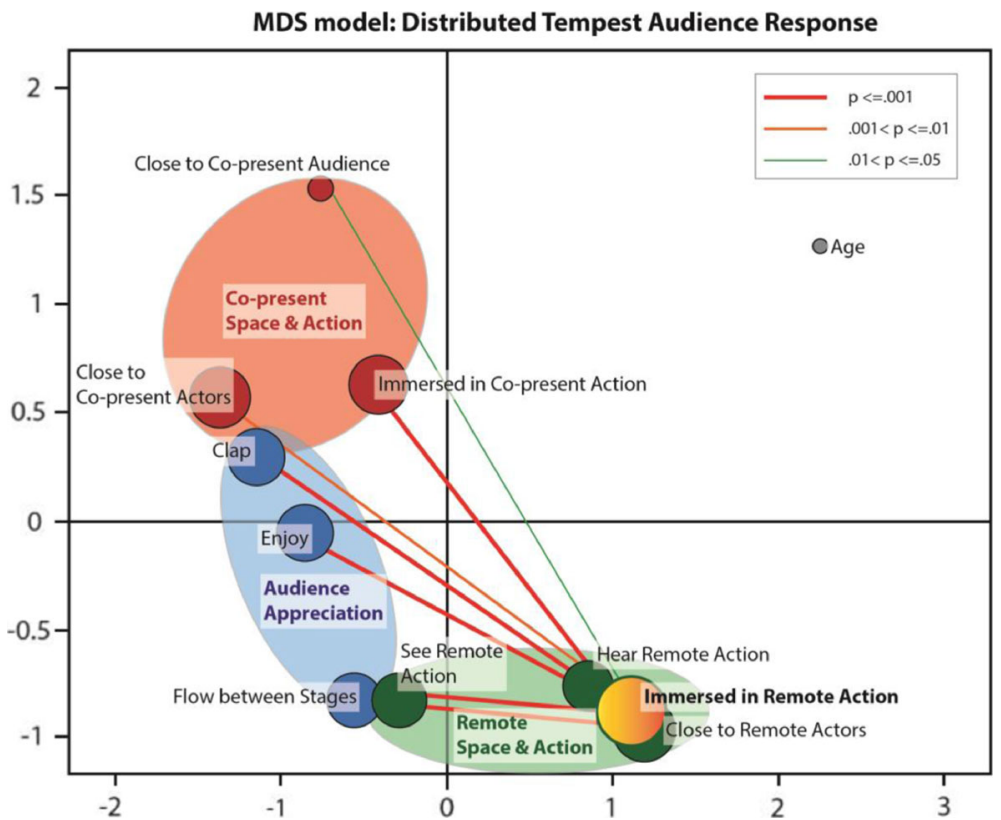

Fig. 10 MDS solution for the distributed tempest 
Table 4 The distributed tempest $p$-values significant correlations

\begin{tabular}{|c|c|c|c|c|c|c|c|c|c|c|c|}
\hline & Age & Enjoy & C-imm & R-imm & C-actors & R-actors & C-aud & Flow & R-See & R-hear & Clap \\
\hline \multicolumn{12}{|l|}{ Enjoy } \\
\hline C-imm & .009 & .000 & & & & & & & & & \\
\hline R-imm & & .000 & .000 & & & & & & & & \\
\hline C-actors & .009 & .005 & .000 & .006 & & & & & & & \\
\hline R-actors & & .000 & .002 & .000 & .012 & & & & & & \\
\hline C-aud & & & .083 & .017 & .025 & .013 & & & & & \\
\hline Flow & & .007 & .065 & .000 & .011 & .000 & .017 & & & & \\
\hline R-See & & .005 & .012 & .000 & .004 & .000 & .054 & .000 & & & \\
\hline R-hear & & .016 & .016 & .001 & .001 & .000 & & .009 & .002 & & \\
\hline Clap & .073 & .000 & .000 & .001 & .004 & .016 & .038 & .003 & .021 & .045 & \\
\hline$p<=.001$ & & 4 & 4 & 7 & 2 & 5 & & 3 & 3 & 3 & 3 \\
\hline$p<=.01$ & 2 & 3 & 2 & 1 & 5 & 1 & & 3 & 3 & 2 & 2 \\
\hline$p<=.05$ & & 1 & 2 & 1 & 3 & 3 & 5 & 2 & 2 & 3 & 4 \\
\hline$p<=.1$ & 1 & & 2 & & & 1 & 2 & 1 & 1 & & 1 \\
\hline Total Weight & 7 & 27 & 28 & 33 & 29 & 30 & 12 & 26 & 26 & 24 & 27 \\
\hline
\end{tabular}

C-aud: How close did you feel to the audience in the room where you were?

Flow: How well did the action flow between the two locations?

R-see: How well could you see the action in the remote location?

R-hear: How well could you hear the actors in the remote location?

Clap: How loud did you clap at the end of the performance?

' $C$ ' refers to co-located experience and ' $R$ ' to the remote experience.

Figure 10 shows the MDS solution for The Distributed Tempest. Remote Immersion co-varies most strongly with other variables. The $p$-values that were shown in Table 3 are shown in thick red lines (weight $=4$ ), one thinner orange line (weight $=3$ ) and two thin green lines (weight $=2$ ).

Age, incidentally, correlated significantly with being immersed in the co-present action and co-present actors (both $p=.009$ ). The older audience was more engaged with the co-present action whereas this seemed less the case for the younger audience, possibly due to a younger audience being less perturbed by the remote action.

Mostly, in the bottom right quadrant, we see variables relating to remote action and in the top left quadrant those relating to co-present action, with audience appreciation taking up an intermediary position (in the bottom left quadrant). It seems to make sense that the flow between the two locations is closer to the remote action and that applause is closer to the copresent side, given the role it played in the live performance of Waiting for Godot.

In a way the data indicate that being (able to be) immersed in the remote action was key to a good distributed theatre experience. Figure 11 shows a histogram for being immersed in the remote action, spanning the whole range between 0 (not at all) and 100 (very).

To highlight the difference in level of immersion amongst the participants, we give some examples of what the top $25 \%$ liked about the performance, i.e. those who scored their remote immersion as higher than 74; those who were deeply immersed in the remote action.

"Novel experience to highlight real possibility \& remote theatre being experienced as close to live as possible." 


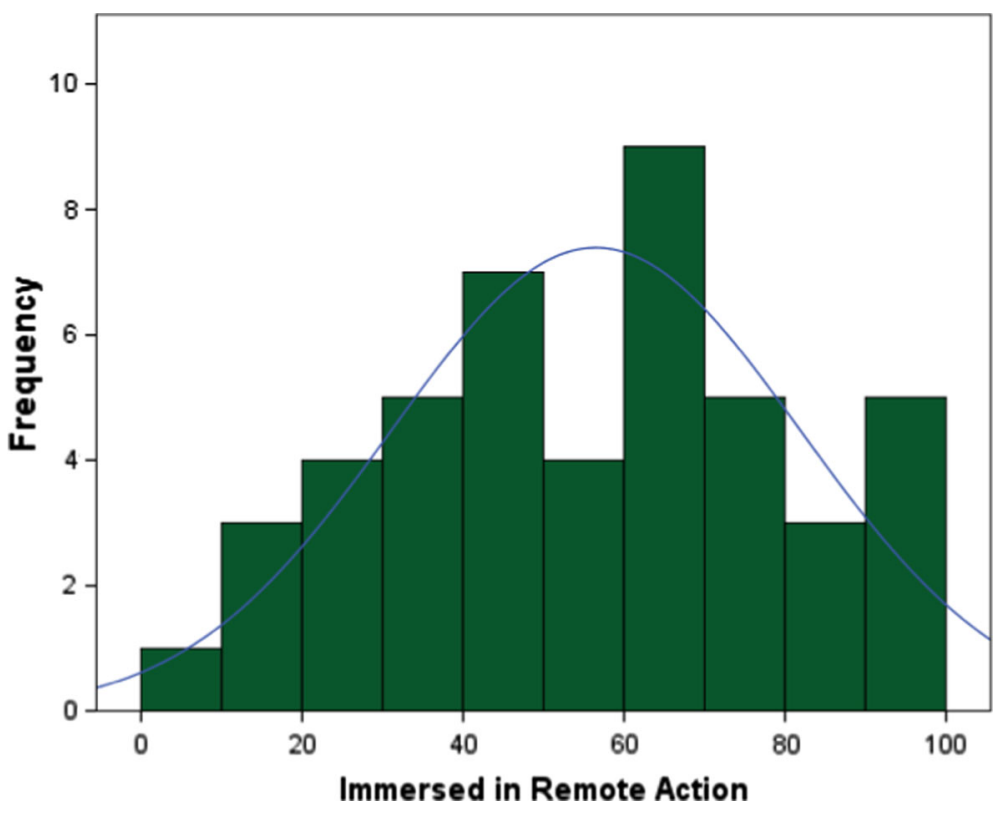

Fig. 11 Histogram for immersed in remote action

"Really great idea, loved how seamlessly the characters transferred between on screen and real life. Amazing how it all worked out looking at the amount of tech. Great!" "Exciting, innovative, captivating, unexpected. Marvelled at the skill of the direction \& acting as it was so slick despite the many technical elements. Atmospheric lighting. Great set. Adored the delightful puppets. Dazzled by the clever technical/visual tricks. All the different camera angles kept your attention, so that it was impossible to drift. I feel kids would hugely benefit from this facet of the experience. A lot going on, so hard to get bored!"

In the same vein, we looked at what the bottom $25 \%$, those who rated remote immersion below 36 , did not like; i.e. those for whom it did not work.

"Less engaging - did not always join together smoothly \& therefore disrupted the narrative." "The engagement between characters off screen to on screen, very disjointed \& difficult for the actors to truly connect. Voice delay was a little distracting. Music \& sound from other venue very distant. Story lost its strength, difficult to engage with the performance as a whole."

"The sound quality - that prevented a sense of immersion more than any disparity between visuals. Get the sound quality up and it would be truly brilliant."

\section{Discussion}

\subsection{Research context and motivation}

The practice of distributed theatre, where the action is played out across two or more Internet connected performance spaces, has reached some maturity but has, as yet, not been a big 
commercial success. In contrast, there is a growing trend for some of the larger theatre companies to regularly stream their live shows to remote locations; often cinemas which have high quality (and expensive) projectors installed. This offers a unique opportunity to people being able to see a show that they normally would not be able to attend because of geographical distance and/or cost. Streaming provides an extra stream of revenue for theatre companies and extends their brand worldwide.

We were fortunate to evaluate the audience response to both distributed and streamed technologies. As we reviewed existing literature on distributed and streamed audience evaluations, we found that quantitative audience response analysis is still rather scarce and might be in need of some added depth in analysis.

\subsection{Field trials, intensity and cohesion}

We report on two field trials. The first concerned a comparison between an audience attending a live theatre performance of Waiting for Godot (the co-present audience) and an audience watching an encore, a recording of the live performance (the remote audience). The second field trial evaluated the audience response to a performance of The Distributed Tempest where the action was played out between two locations, each with its own audience, i.e. both audiences were exposed to co-present and remote aspects of the performance.

We introduce two concepts that we believe provide useful metrics when evaluating the copresent and remote audience response: intensity and cohesion, each looking at the audience response from a different angle.

Intensity relates to how intensively co-present and remote aspects of a performance are rated by an audience. Cohesion, relates to how a performance as a whole, the combination of co-present and remote aspects, affects an audience. Cohesion was operationalised as how (strongly) aspects of the performance were correlated.

\subsection{Intensity of the remote audience experience}

When watching a streamed live theatre performance it is almost inevitable that the projected image, no matter how expensive the projector is, will be less vivid than what one would experience when being in the same room as the actors; as such the intensity of seeing a streamed performance is lower than being co-present. The same may be true for hearing the (remote) performance. Thus remote aspects of a performance are likely to be experienced as less intense.

Compared to the co-present audience experience, the encore of Waiting for Godot was experienced as less clear to see and hear. Although they rated their enjoyment of the encore relatively high as they did how immersed they were, how close they felt to the actors and how often they smiled, this was all significantly lower than the co-present audience did. Where the co-present audience experienced a high urge to clap and, indeed, did clap loudly, the encore audience reported a very low urge to clap and there was barely any applause. Where the encore audience is concerned, there may have been group effects at work, similar to a cinema audience, as people seldom clap at the end of a movie.

Likewise, during the performance of The Distributed Tempest all remote aspects were experienced as less intensive than co-present aspects. The audience reported that they felt closer to the actors that were physically in the same room (co-present) where they were and felt more distant to the actors that were in a remote location and were shown on a projection 
screen. One might therefore expect that what is shown on a projection screen is bound to remain less engaging. Is there anything that can be done to bring the co-present and remote action closer together? Ideas in the realm of the concept of telepresence exist, but are yet to be applied to distributed performances.

\subsection{Cohesion of the remote audience experience}

However, the encore of Waiting for Godot and The Distributed Tempest differed in how cohesive the performance was experienced.

The co-present audience of Waiting for Godot experienced a highly cohesive performance culminating in the applause at the end as a true catharsis. In sharp contrast, the encore resulted in fewer significant inter-correlations, led to a more dispersed, less cohesive experience, which centred around smiling, an altogether more introvert expression of appreciation.

The close integration of the remote action with the co-present action in The Distributed Tempest through set-design and applying cinematic techniques, including using scripted camera-action resulted overall in a more cohesive audience experience. Albeit, as the results show, there was a small section of the audience for whom the remote experience did not work.

One could justifiably argue that the questionnaire for Waiting for Godot was somewhat different than the one used for The Distributed Tempest. As such we can only state that there was quantitative evidence that the encore of Waiting for Godot resulted in a less cohesive audience experience than the live performance. It seems inevitable that, in the absence of standardised remote audience experience questionnaires, each performance will be evaluated using bespoke questions relevant to the performance in question.

The nature of The Distributed Tempest field trial prevented us from conducting a more controlled experiment, e.g. comparing the distributed version with the stage version. All the same we suggest that there is mileage in looking at differences (as done by others) as well as at similarities (not currently done) when evaluating the audience response. We hope that the notion of cohesion at least makes sense intuitively.

In our field trials, cohesion was of a positive nature. It is of course possible that a poorly staged performance also will result in a cohesive experience, but a negative one.

We reported previously [66] that intensity of home viewing is significantly lower compared to that of a co-present theatre audience and an audience attending an encore at a cinema. We found the same for our small sample watching the Tempest at home, either on a computer, a $\mathrm{TV}$ or projected on the living room wall. Not reported here, the experience was 'cohesive' all the same.

\subsection{Enabling low budget theatre companies}

Streaming live performances is very much the prerogative of well-funded theatres. Part of our research was focused on providing enabling technologies to low budget theatre companies, such as, in the case of the current study, Miracle Theatre, to give them an opportunity to explore what live streaming would mean to them. What investment is required, how can they make money out of this and how minimise risks? The risks may be considerable.

The lifeblood of Miracle Theatre is the loyal following they built up across 35 years, touring nationally. As such they need to weigh up the benefits that streaming offers reaching a wider audience in locations they normally would not visit against the damage that a failed streaming event could cost them reputation wise. In addition, they might, for instance, stream 
to low budget venues that cannot afford the high quality projectors of mainstream cinemas resulting in lower quality reproduction. What are the effects of such lower quality? At least for now, a theatre company such as Miracle Theatre is taking a brave risk, living on the bleeding edge of technology.

\subsection{Benefits of a script based approach}

Using film techniques, such as those that enhance the communicative power (generating empathy) of facial language of an actor during a theatre performance, in a way that Mirror Neuron theory predicts, could benefit the efficacy of mediated performance. To that end, the script-based approach [32] for controlling dynamic screen contents and PTZ cameras in (distributed) theatre would make a useful tool for low budget performance companies to stream their performances. Available PTZ cameras range from reasonably priced to high-end devices. The approach could be implemented in industry standard software, such as Qlab [55], or dedicated toolsets with user interfaces to support the authoring, rehearsal and execution of production scripts during the play. The approach allows for different degrees of automation: fully predefined scripts that merely need to be synced with the acting on one end of the spectrum, and fully automatic systems on the other. The latter extreme is currently still subject for further research [31], but integrating automatically extracted cues is not a completely far-fetched aim. Cues are information about the scene extracted in real-time. Any kind of sensor could be used, for example to infer an actor's position on the stage, or to understand which part of the play they are currently acting by analysing body language and audio (speech, singing, etc.).

\subsection{Audience as community}

Interestingly, the encore audience felt less close to the people in the room with them than the (co-present) audience at the live performance did. One could argue that being present at a live performance, being face to face with and in ear-shot of the actors and the stage design and lighting drawing the audience in, might be at the expense of being aware of fellow audience members. However the opposite was the case. Directly or indirectly, watching a projection screen seems to detract from a sense of co-located audience community.

On the other hand, the encore audience felt significantly closer to the remote audiences elsewhere (Exeter, Plymouth and St Agnes) than the audience at the live performance felt to the three locations where the live performance was streamed to.

Thus co-present audience members feel part of the other people watching with them physically in the same room but are completely oblivious to the remote audiences, in spite of being informed about the streaming and seeing a four person camera crew at work. We suggest that making the presence of remote audiences felt in the theatre of origin, through some sort of visualization and sonification, may help to connect co-present and remote audiences thereby enhancing the theatre experience for audience and actors alike.

The design of a field trial often requires some hard decisions. For The Distributed Tempest this meant a strong focus on making the performance work, artistically, technology wise and technical. Placing microphones close to the actors' mouth prevented audio-feedback and the actors came across very clearly to the remote location, but this resulted in a lack of audio presence between the two audiences.

The average age of the Miracle Theatre followers is within the $40-50$ years age bracket. We found that the older people were more immersed in the co-present action than the younger 
audience members, who might be able to divert their attention more equally between copresent and remote action and actors. However, there was no significant negative correlation between age and remote immersion. Moreover, although not reported here, the older theatre goers were more likely to have seen NT Live shows i.e. the older audience had had more exposure to the streaming technology.

We have reported [71] the results of a laboratory experiment using Galvanic Skin Response (GSR) to measure audience attention, where we compared a co-present with a remote audience in a configuration where they could see and hear each other via screens and loudspeakers. Although overall the remote GSR readings were lower than those of the co-present audience, this only reached significance during a few minutes of the performance. We see this as supporting evidence that connecting audiences creates if not a sense of community then at least a similar physiological response.

\section{Conclusion}

We introduce two concepts to evaluate audience response: intensity, relating to how different aspects of a performance are rated, and cohesion, relating to how a performance as a whole affects an audience.

Streamed theatre performances are likely to be experienced as less intense by a remote audience but have the potential to still come across cohesively; cinematographic techniques may be conducive to this process. While some ideas can be borrowed from telepresence research, they are yet to be applied and evaluated in the domain of distributed performances and remote audiences.

We found indications that providing some form of remote audience interaction will aid in creating a tighter audience community and will benefit audience and performers alike. It is well known that feedback from the local audience is important for actors, even their mere presence as motivation. How to make actors aware of remote audiences? Which of the human senses could be best exploited to suit this need? These remain open questions for further research.

In addition to organisations specialising in on-line performance, we expect more traditional low budget performance companies to start to populate this area of interactive streamed performances. The likelihood is high that this will create a demand for readily available, affordable technologies supporting distributed interactive performance.

Acknowledgements The research leading to these results has received funding from several sources: the European Community's Seventh Framework Program under grant agreement no. ICT-2011-287760 (Vconect), British Telecom, the National Endowment for Science, Technology and the Arts (NESTA) and the Arts and Humanities Research Council (AHRC). We want to thank all at Miracle Theatre, Dogbite Studios, the Falmouth Maritime Museum, the JointEffort video crew, and all partners in these collaborative research endeavours.

\section{References}

1. Anderson NH (1970) Functional measurement and psychophysical judgment. Psychol Rev 77(3):153-170

2. Auslander P (1999) Liveness: performance in a mediatized culture. Routledge, Oxon

3. Bakhshi, H., J. Mateos-Garcia and D. Throsby. (2010) Beyond Live. http://www.nesta.org. uk/publications/beyond-live (last accessed 04/2016) 
4. Barker M, Brooks K (1998) Knowing audiences: Judge Dredd - Its friends, fans and foes, University of Luton Press

5. Barker M (2013) Live to your local cinema: the remarkable rise of livecasting. Palgrave Macmillan

6. BEAMING - Being in Augmented Multi - Modal Naturally - Networked Gatherings, EU FP7 project, http://beaming-eu.org/ (last accessed 04/2016)

7. Berry M, Geelhoed E, Scott B, Towell P, Ukleja A (2015) Miracle theatre: live \& digital research and development report London: Nesta, http://artsdigitalrnd.org.uk/wp-content/uploads/2013/07/MiracleTheatre-Research-and-Development-Report2.pdf (last accessed 04/2016)

8. Birringer J (2008) Performance, technology \& science. PAJ Publications, New York

9. Boerner S, Jobst J, Wiemann M (2010) Exploring the theatrical experience: results from an empirical investigation. Psychol Aesthet 4:173-180

10. Boerner S, Jobst J (2013) Enjoying theater: the role of visitor's response to the performance. Psychol Aesthet, Creat Arts 7:391-408

11. Brown AS, Novak JL (2007). Assessing the intrinsic impacts of a live performance. WolfBrown

12. Cavendish D (2010) Sir Nicholas Hytner on NT Live Telegraph On-line 24th May 2010 http://www. telegraph.co.uk/culture/theatre/7741304/Sir-Nicholas-Hytner-on-NT-Live.html (last accessed 04/2016)

13. Causey M (1999) Test of the Double: The Uncanny Performer in the Space of Technology. Theatre Journal, Vol. 51, no 4. Theatre and Technology, p 383-394. John Hopkins University Press

14. Cerrato-Pargman T, Rossitto C, Barkhuus L (2014) Understanding audience participation in an interactive theater performance. Proceedings of NordCHI'14, Helsinki, Finland. 608-617

15. Chartrand TL, Bargh JA (1999) The chameleon effect: the perception-behavior link and social interaction. J Pers Soc Psychol 76(6):893-910

16. Clark HH, Brennan S (1991) Grounding in communication. In: Resnick LB, Levine J, Teasley SD (eds) Perspectives on socially shared cognition. APA Press, Washington

17. ControlBooth, Thread “Pepper's Ghost / Projection surface ?", https://www.controlbooth. com/threads/peppers-ghost-projection-surface.30412/\#post-271875 (last accessed 04/2016)

18. Corness G, Carlson K, Schiphorst T (2011) Audience empathy: a phenomenological method for mediated performance. Proceedings Creativity and Cognition, 127-136. ACM, New York

19. Cremona C (2011) Skype and videoperformance: relational screens. 17th International Symposium on Electronic Art, Istanbul

20. CultureHub, center for art and technology, New York. http://www.culturehub.org/ (last accessed 04/2016)

21. Dixon S (2007) Digital performance, a history of new media in theatre, dance, performance art, and installation. MIT Press, Cambridge

22. Dog Bite Film Crew, http://www.dogbitefilmcrew.com/ (last accessed 04/2016)

23. Fadiga L, Craighero L, Buccino G, Rizzolatti G (2002) Speech listening specifically modulates the excitability of tongue muscles: a TMS study. Eur J Neurosci 15:399-402

24. Gazzola V, Aziz-Zadeh L, Keysers C (2006) Empathy and the somatotopic auditory mirror system in humans. Curr Biol 16(18):1824-1829

25. Geelhoed E, Williams D, Albright S, Hubley T (2007) User-centred approach to achieving the halo experience, paper presented at eChallenges e-2007 Conference The Hague 24-26 October 2007.

26. Geelhoed E, Parker A, Williams DJ, Groen M (2009) Effects of latency on telepresence. HP labs technical report: HPL-2009-120 http://www.hpl.hp.com/techreports/2009/HPL-2009-120.html (last accessed 04/2016)

27. Geelhoed E, Stenton P, Singh-Barmi K, Biscoe I (2014) Necessidades dos usuários de espaços de performances imersivas mediatizadas, (User Requirements in Immersive Mediated Performance). Revista Mapa, Vol. 1, No 1, 2014, Brazil. http://www.portalseer.ufba.br./index.php/mapad2/issue/view/870/showToc (last accessed 04/2016)

28. Jackson PL, Brunet E, Meltzoff AN, Decety J (2006) Empathy examined through the neural mechanisms involved in imagining how I feel versus how you feel pain. Neuropsychologia 44(2006):752-761

29. Jabbi M, Swart M, Keysers C (2007) Empathy for positive and negative emotions in the gustatory cortex. NeuroImage 34:1744-1753

30. Joint Effort Studios, http://jointeffortstudios.com/ (last accessed 04/2016)

31. Kaiser R, Weiss W (2014) Media Production, Delivery and Interaction for Platform Independent Systems: Format-Agnostic Media, chapter Virtual Director, pp. 209-259. Wiley

32. Kaiser R, Ursu MF, Falelakis M, Horti A (2015) Enabling distributed theatre performances through multicamera telepresence - Capturing system behaviour in a Script-Based Approach, Proceedings of the 3rd International Workshop on Immersive Media Experiences (ImmersiveME '15), pp. 21-26.

33. Kaptein M, Nass C, Markopoulos P (2010) Powerful and consistent analysis of Likert-type rating scales. Proceedings of CHI 2010, Atlanta, USA: 2391-2394

34. Kline P (1986) A Handbook of Test Construction. Introduction to Psychometric Design. Methuen \& Co, London

35. Kozel S (2007) Closer, performance, technologies, phenomenology. The MIT Press, London 
36. LABoral Centro de Arte y Creación Industrial, http://www.laboralcentrodearte.org/en/recursos/obras/telematicdreaming-1992/ (last accessed 04/2016)

37. Latulipe C, Carolina C, Carroll EA, Lottridge D (2011) Love, hate, arousal and engagement: exploring audience responses to performing arts. Proceedings of CHI 2011, Vancouver, Canada: 1845-1854

38. Leslie KR, Johnson-Frey SH, Grafton ST (2004) Functional imaging of face and hand imitation: towards a motor theory of empathy. NeuroImage 21:601-607

39. Li J, Martens JB, van Wijk JJ (2010) A model of symbol size discrimination in scatterplots. Proceedings of CHI 2010, Atlanta, USA 2553-2562

40. Lin Y-W, Williams AE (2014) Projecting the voice: observations of audience behaviours in ICT-mediated contemporary opera. New Rev Hypermedia Multimedia 20(3):207-223

41. Likert R (1932) A technique for the measurement of attitudes. J Soc Psychol 5:228-238

42. McFarland DH (2001) Respiratory markers of conversational interaction. J Speech, Lang Hear Res 44:128-143

43. Miracle Theatre, http://www.miracletheatre.co.uk/ (last accessed 04/2016)

44. Miracle Theatre, Vconect's The Distributed Tempest approach: https://www.youtube.com/watch?v= GXEcJX1LIbg (last accessed 04/2016)

45. Miracle Theatre, Interview about Vconect's The Distributed Tempest: https://www.youtube.com/watch?v= O-VJPvrm4-8 (last accessed 04/2016)

46. Musion Das Hologram Ltd., http://www.musion.co.uk/ (last accessed 04/2016)

47. Musion Eyeliner, Gorillaz at MTV Europe Awards 2005, http://www.eyeliner3d.com/gorillaz_mtv_awards. html (last accessed 04/2016)

48. National Theatre Live, http://ntlive.nationaltheatre.org.uk/ (last accessed 04/2016)

49. Naugle L (2002) Distributed choreography, a video-conferencing environment. J Perform Art 24(2):56-62

50. Panoply, Dimanche Rouge (2011) http://panoplylab.wordpress.com/tag/social-practices-arts-network/ (last accessed 04/2016)

51. Paul Sermon: Telematic Dreaming - Statement, http://www.paulsermon.org/dream/ (last accessed 04/2016)

52. Pepper's Ghost, https://en.wikipedia.org/w/index.php?title=Pepper\%27s_ghost\&oldid=711533183 (revision of 23 March, 2016)

53. Poéticas Tencológicas: Corpoaudiovisual, http://www.poeticatecnologica.ufba.br/ (last accessed 04/2016)

54. Porta (Giambattista della): Magia Naturalis, https://en.wikipedia.org/w/index.php?title=Magia Naturalis\&oldid=711143637 (revision of 21 March, 2016)

55. Qlab, http://Figure53.com/qlab/ (last accessed 04/2016)

56. Rizzolatti G, Arbib MA (1998) Language within our grasp. Trends Neurosci 21(5):188-194

57. Rizzolatti G, Craighero L (2004) The mirror-neuron system. Annu Rev Neurosci 27:169-192

58. Santana I (2006) Dança na Cultura Digital. Salvador:EDFBA. 204pag. 2006. ISBN 85-232-0415-6. Salvador : Editora da UFBA, 2006, v.1. p.204

59. Sas C, O'Hare GM (2003) Presence equation: an investigation into cognitive factors underlying presence. Presence 12(5):523-537

60. Schutt B (2011) Case study: national theatre live ft.com/Management Aug 24th 2011

61. Sermon P (1992) Telematic dreaming: http://vimeo.com/20054617 (last accessed 04/2016)

62. Shrader A (2015) A comparison of audience response to live and recorded theatre performances, research honours degree thesis, Department of Psychology Marietta College, Marietta, OH, April 8, 2015

63. Shockley K, Santana MV, Fowler CA (2003) Mutual interpersonal postural constraints are involved in cooperative conversation. J Exp Psychol Hum Percept Perform 29(2):326-332

64. Sonic Foundry Mediasite, http://www.sonicfoundry.com/mediasite/ (last accessed 04/2016)

65. Stenslie S (2003) Erotogod, https://stensliehome.wordpress.com/2014/06/19/erotogod/ (last accessed 04/2016)

66. Stenton P, Geelhoed E, Pollard S, Porter G, Bellaar-Spruijt V (2012) Extending the theatre experience: the potential for wearable and on-stage cameras. Ubiquity: Journal of Pervasive Media, Vol 1, pp 33-64, Intellect Ltd

67. Stinehelfer B (2012) Skype Duet, http://per-aspera.net/skype-duet/ (last accessed 04/2016) 
68. Stone H, Sidel J, Oliver S, Woolsey A, Singleton RC (1974) Sensory evaluation by quantitative descriptive analysis. Food Technol 1974:24-34

69. Vladica V, Davis CH (2013) Value propositions of opera and theater live in cinema. http://www.ryerson. $\mathrm{ca} / \sim 5$ davis/publications/Vladica-Davis\%20-\%20value\%20propositions\%20of\%20live\%20cinema $\% 20$ \%201\%20May\%202013.pdf (last accessed 04/2016)

70. Wang C, Geelhoed E, Stenton P, Cesar P (2014) Sensing a live audience. Proceedings of CHI 2014, Toronto, Canada: 1909-1912

71. Wang C, Zhu X, Geelhoed E, Biscoe I, Röggla T, Cesar P (2016) How are we connected? Measuring Audience Galvanic Skin Response of Connected Performances, in Proceedings of the International Conference on Physiological Computing Systems, (PhyCS 2016), July 27 - July 28, 2016, Lisbon, Portugal

72. Williams D, Kegel I, Ursu MF, Cesar P, Jansen J, Geelhoed E (2015) Experiments with Distributed Theatre, IEEE, MultiMedia, July-September 2015, Vol. 22, No. 3. Published by the IEEE Computer Society: Social Multimedia and Storytelling. page 4-9

73. Williams D, Kegel K, Ursu MF, Cesar P, Jansen J, Geelhoed E, Horti A, Frantzis M, Scott B (2015) A Distributed Theatre Experiment with Shakespeare, the ACM, MM'15 conference October 26-30, 2015, Brisbane, Australia

74. Wilson M, Wilson TP (2005) An oscillator model of the timing of turn-taking. Psychon Bull Rev 12(6):957-968

75. Young FW, Hamer RM (1987) Multidimensional scaling: history, theory, and applications. Lawrence, Erlbaum Associates, London

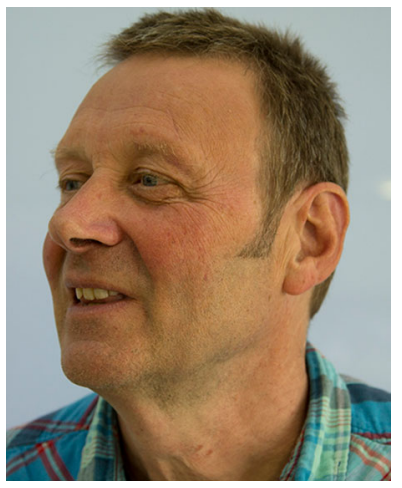

Drs Erik Geelhoed is an experienced researcher with a long history of experimental design and analysis in HCI and psychophysics. He worked at Hewlett-Packard's global research labs for 17 years collaborating with large and small businesses, funders and platform builders around the world. He is an accomplished collaborator who brings an accessible and professional expertise for uncovering the human requirements for interaction with technology and social networks. At Falmouth University he has extended his work with SME's and startups helping them collect data to inform their strategy. As an experimental psychologist he has written over 60 publications and presented his work to researchers and businesses in Europe, Asia and the US. His requirements studies: from focus groups and interviews to lab studies and field trials have informed the design and targetting of technology. He is invaluable in understanding the user requirements within the entrepreneurial ecosystem and their consequences for how the technology should be shaped to optimise the activity within it. 


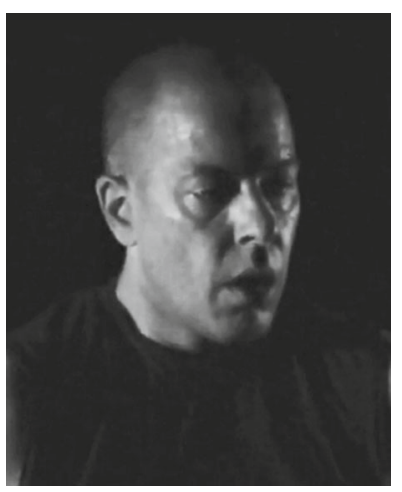

Kuldip Singh-Barmi trained at The Northern School of Contemporary Dance and has been performing, teaching and improvising eversince. He was a founder member of CandoCo Dance Company and has worked with choreographers and companies such as Emilyn Claid, Lloyd Newson, Siobhan Davies, Darshan Singh Bhuller (Singh Productions), Annabel Arden (Theatre de Complicite), Kwesi Johnson (Kompany Malakhi) RJC Dance Company, Fidget Feet Arial Dance/Theatre Company, Attik Dance and Company Pyke. Kuldip has taught and performed extensively nationally and internationally. Currently Kuldip is A Senior Lecturer in the Dance \& Choreography Department at Falmouth University.

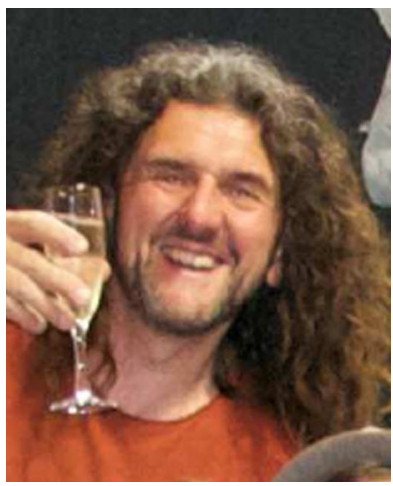

Ian Biscoe is a producer, artist, researcher and engineer with degrees in architecture and landscape architecture. He founded a number of international companies in the fields of process control, aerospace, mobile communications and entertainment, where he specialised in complex systems integration challenges. His explorations of the boundaries of physical, virtual and augmented realities are conducted using a range of media, in performance and installation, working with collaborators from the disciplines of theatre, dance and music. Ian was a key member of the European Commission funded FP7 Vconect programme (investigating low latency video networking for distributed performance) and is currently providing real-time streaming and systems integration expertise for the AHRC supported Online Orchestra research project. Ian is also studying for a $\mathrm{PhD}$ in cognitively enabled built environments. 


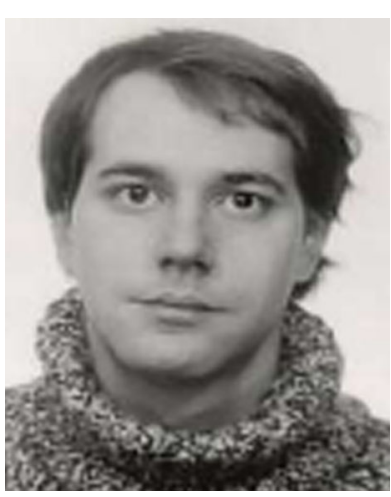

Pablo Cesar leads the Distributed and Interactive Systems research group at CWI. He received his PhD from the Helsinki University of Technology in 2006. He has (co)authored over 70 articles (conference papers and journal articles) about socially-aware multimedia, multimedia systems and infrastructures, multimedia content modeling, and user interaction. He is involved in standardization activities (e.g., W3C, MPEG, ITU) and has been active in a number of European projects such as REVERIE, Vconect, TA2, iNEM4U, Passepartout, and SPICE. He is coeditor of the book "Social Interactive Television: Immersive Shared Experiences and Perspectives" and has given tutorials about multimedia systems in prestigious conferences such as ACM Multimedia, ACM CHI, and the WWW conference.

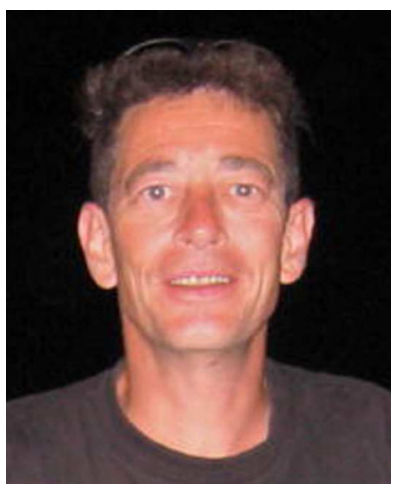

Jack Jansen is a researcher at Centrum Wiskunde en Informatica (CWI), with over 25 years of experience in multimedia and distributed systems. Empowering people to put available technology to a use they themselves envision is his driving principle. This results in activities ranging from languages, such as Python, via web standardization work (SMIL, Rich Web Application Backplane) to implementing systems for accessible and reusable multimedia (Ambulant). Recently, he has finally started to pursue a PhD. Webpage: http://homepages. cwi.nl/ jack/ 


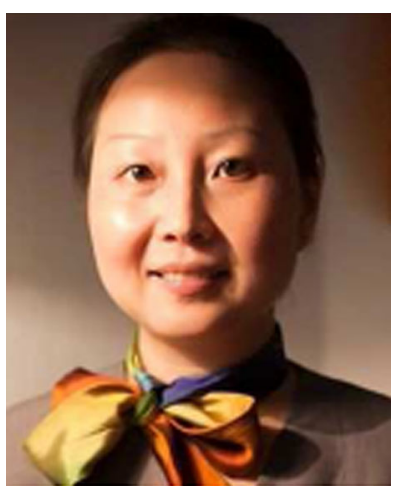

Chen Wang is the PhD student at the Distributed and Interactive Systems (DIS) group at CWI (The National Research Institute for Mathematics and Computer Science in the Netherlands). She received the B.Sc degree in Telecommunication Engineering, Nanjing University of Post\&Telecommunications, China, and M.Sc in Electrical Engineering from Delft University of Technology, the Netherlands. Chen Wang focused on audience research by using physiological sensors during the research period, and Chen Wang and the other team members successful conducted the user studies in theater performance, video consumption, and the distance learning. The related research results have been selected by the top conference, such as ACM CHI, and NordiCHI. Recently she is actively participated in the Public Private Partnership with Xinhuanet: one of the biggest news agency in China, where the user studies will be conducted to investigate audience experience in theater performance and video consumptions.

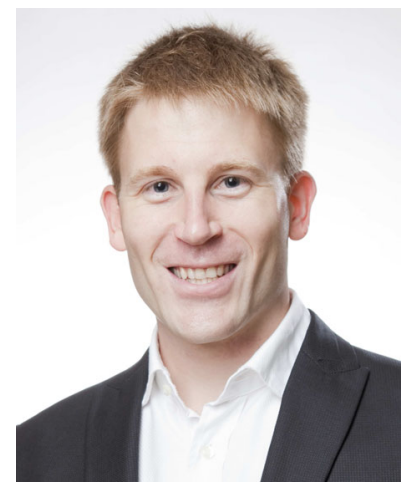

Rene Kaiser is key researcher at JOANNEUM RESEARCH, Graz, Austria. His main research expertise and interest is in interactive personalized access to multimedia content, both in technical approaches and understanding user needs. Rene is interested in various application areas of social computing, primarily videoconferencing and telepresence, non-linear video production, live event broadcast, and exploiting media content to support knowledge transfer. Particular research focus is on "Virtual Director" technology, automatic decision making for the framing and presentation of live video streams on screens. More information: https://about.me/rene.kaiser. 